\title{
IPR 1.0: an efficient method for calculating solar radiation absorbed by individual plants in sparse heterogeneous woody plant communities
}

\author{
Y. Zhang, W. Chen, and J. Li \\ Canada Centre for Mapping and Earth Observation, Natural Resources Canada, Ottawa, Canada \\ Correspondence to: Y. Zhang (yu.zhang@nrcan.gc.ca)
}

Received: 30 October 2013 - Published in Geosci. Model Dev. Discuss.: 18 December 2013

Revised: 4 June 2014 - Accepted: 6 June 2014 - Published: 10 July 2014

\begin{abstract}
Climate change may alter the spatial distribution, composition, structure and functions of plant communities. Transitional zones between biomes, or ecotones, are particularly sensitive to climate change. Ecotones are usually heterogeneous with sparse trees. The dynamics of ecotones are mainly determined by the growth and competition of individual plants in the communities. Therefore it is necessary to calculate the solar radiation absorbed by individual plants in order to understand and predict their responses to climate change. In this study, we developed an individual plant radiation model, IPR (version 1.0), to calculate solar radiation absorbed by individual plants in sparse heterogeneous woody plant communities. The model is developed based on geometrical optical relationships assuming that crowns of woody plants are rectangular boxes with uniform leaf area density. The model calculates the fractions of sunlit and shaded leaf classes and the solar radiation absorbed by each class, including direct radiation from the sun, diffuse radiation from the sky, and scattered radiation from the plant community. The solar radiation received on the ground is also calculated. We tested the model by comparing with the results of random distribution of plants. The tests show that the model results are very close to the averages of the random distributions. This model is efficient in computation, and can be included in vegetation models to simulate long-term transient responses of plant communities to climate change. The code and a user's manual are provided as Supplement of the paper.
\end{abstract}

\section{Introduction}

Climate change is expected to alter the composition (species types and their density), structure (heights, leaf area, crown size, etc.) and spatial distribution (locations and extents) of terrestrial ecosystems (Cramer et al., 2001), which directly affect animals' habitats and human applications of the lands, and have strong feedbacks on the climate system (Fischlin et al., 2007). Transitional zones between biomes, or ecotones, are particularly sensitive to climate change and could provide early signs of climate change impacts (Fankhauser et al., 2001). Transitional zones are usually heterogeneous with sparse trees, such as the treeline between boreal forest and Arctic tundra (the width of the treeline usually ranges about $100 \mathrm{~km}$; Timoney et al., 1992), parklands and savannah. Field observations and remote-sensing data (aerial photos and satellite images) have detected increases in greenness (Xu et al., 2013) and changes in density and height of trees and shrubs in the transitional zones between boreal forest and Arctic tundra (Gamache and Payette, 2004; Sturm et al., 2001; Tape et al., 2006). Relative changes in height, crown size, and the density of trees, shrubs and herbs usually occur before major shifts in biomes as projected by some vegetation models (e.g. Gamache and Payette, 2004; Tape et al., 2007; Callaghan et al., 2005). Novel ecosystem types could appear as well since individual species independently adjust to climate forcing (Overpeck et al., 2003; Walker et al., 2006). To understand and predict these transient changes, it is essential to consider light competition among different species in plant communities (the words "light" and "radiation" are used interchangeably in this paper). In sparsely vegetated regions, the solar radiation received on the ground 
is important as well for soil thermal and hydrological conditions, especially for permafrost conditions in cold regions.

Different methods have been developed to calculate solar radiation absorbed by plants. The major approaches include the one-big-leaf method (considering the whole canopy as one layer, e.g. Sellers et al., 1992), the two-big-leaf method (dividing the canopy into sunlit and shaded leaves, e.g. Norman, 1980; Wang and Leuning, 1998), using Beer's law to estimate radiation distribution in canopies assuming canopies are uniform turbid media (Monsi and Saeki, 1953), and two-stream approximation considering scattering and absorption of down-welling and up-welling light in canopies (Dickinson, 1983). All these approaches assume that the canopy is a uniform layer covering the entire study area. More detailed numerical canopy radiation models have been developed for energy balance and for remote-sensing applications (e.g. Cescatti, 1997; Gastellu-Etchegorry et al., 2004; Kobayashi and Iwabuchi, 2008; Li et al., 1995; Prince, 1987; Myneni et al., 1995; Wang et al., 2007). However, these models are time consuming in computation and usually do not pay much attention to light competition among different plant types.

In the past decade, several models have considered the composition of different plant types in plant communities and their competition for light and other resources (e.g. Foley et al., 1996; Sitch et al., 2003; Zhang et al., 2002). For example, Sitch et al. (2003) considered the light competition among plant functional types based on the leaf area index of individual plants and their density, but did not consider the effects of plant heights on light competition. Foley et al. (1996) assumed that trees are always higher than grasses for light competition. Zhang et al. (2002) used a similar approach but considered three strata (upper storey, under storey, and ground growth). Ryel et al. (1990) simulated light competition in multi-species crop communities based on the foliage composition of the species in each canopy layer. These studies considered the vertical structure of the canopies but assumed that the canopy layers/strata are uniform and cover the entire study area continuously. Several studies developed three-dimensional models to simulated radiation distribution in sparsely distributed trees, mainly for fruit orchards (de Castro and Fetcher, 1998; Oyarzun et al., 2007; West and Welles, 1992; Baldocchi and Collineau, 1994). However, the plant communities considered are usually composed of only one type of tree. Therefore there is no light competition among plant species or types. Song and Band (2004) develop a model to simulate the spatial patterns of solar radiation under a forest of discrete crowns. The approach could be improved to calculate solar radiation received by individual plants.

Another issue in vegetation models is their complexity and applicability. Stand-based vegetation models estimate the competition of vegetation types based on average individual plants, and the canopy of each vegetation type is assumed to be continuously distributed (e.g. Foley et al., 1996;
Sitch et al., 2003; Zhang et al., 2002). Such simplification significantly reduces the requirement of input data and computation cost, and the models can be used for large areas spatially explicitly. On the other hand, individual-based vegetation models consider the competition of individual plants (e.g. Sato et al., 2007). Explicit ray tracing methods can also be used to calculate the light interception of individual plants (e.g. Kobayashi and Iwabuchi, 2008). Such models are useful for process understanding. However, their input data requirement and computation cost are high and it is difficult to cover large areas at high spatial resolution with these models.

In this study, we develop an individual plant radiation model, IPR (version 1.0), based on geometrical optical relationships. It is an efficient method to calculate the solar radiation absorbed by average individual plants of different types in sparse heterogeneous woody plant communities (i.e. the canopy is discontinuous and composed of different species or one species but of different ages). Solar radiation under the woody plants is calculated as well. This model may be useful to improve the accuracy of light competition among different vegetation types in stand-based vegetation models. In the paper, we first describe the assumptions and the algorithms of the model. Then we test the model by comparing with the results of the random approach and the two-big-leaf method, and by sensitivity analysis. Some important features and limitations of the model are highlighted in the discussion section.

\section{Methodology}

\subsection{The assumptions of the model}

Natural plant communities, especially in northern high latitudes, are usually composed of trees, shrubs, herbs, mosses and lichens. To simplify the calculation, the IPR model was developed based on the following seven assumptions for plant communities and three assumptions for radiation conditions: (1) the plant community may include woody plants (trees and shrubs), herbs, and mosses/lichens in a large flat area (the area is so large that the margin effects can be ignored); (2) woody plants are higher than herbs, and herbs are higher than mosses/lichens; (3) woody plants can be categorized into several strata based on their heights and crown sizes, which can be different species or one species but of different ages; (4) the plants of each woody stratum are distributed somewhat regularly (equivalent to the average of random distributions), mixed with plants of other woody strata and are trying to avoid overlapping with one another (Ward et al., 1996); (5) the herb stratum is distributed uniformly, and is treated collectively without considering individual plants; (6) mosses/lichens cover the entire ground or cover part of the ground randomly; (7) the crowns of woody plants are treated as rectangular boxes, and the leaf area density is distributed uniformly within a box; (8) the sky diffuse 
radiation is from the whole hemisphere and is in isotropic distribution (Goudriaan, 1977); (9) scattered radiation generated from reflection and transmission in canopies is in all directions, and the recollision probability remains constant in successive scattering (Panferov et al., 2001; Smolander and Stenberg, 2005); and (10) both the sky diffuse radiation and the scattered radiation are uniformly distributed in a crown.

There are several reasons for the treatment of crowns as somewhat regularly distributed but not exactly regular (assumption 4). First, plants tend to be distributed somewhat regularly because of the competition (Ward et al., 1996); second, although plants of one stratum can be distributed regularly based on geometry assuming equal spacing among nearest plants (e.g. at centres and nodes of hexagons), it is difficult to distribute plants of two or more strata without overlapping among plants of different strata; and third, the fractions of sunlit leaf area can be different between the average of random distribution and exact regular distribution. Crowns of woody plants can be in different shapes depending on the genetic features of the species and the environment. To simplify the calculation, we treated crowns as rectangular boxes. Oyarzun et al. (2007) also treated fruit-tree crowns as prisms in orchards. However, their prism-shaped crowns are always aligned with the rows of the plants in an orchard, while we assumed that a crown looks like a rectangular box (or looks like a rectangle with the same optical length) in all azimuth directions and there is always a side facing the sun considering that crowns are usually symmetrical. Crowns, especially when they are large and dense, usually have much less leaves in the centre of the crown, thus the horizontal optical length of the crown is not proportional to its geometric length. More importantly, this simplified treatment of the crowns allows quasi-analytical solutions and greatly improves the efficiency and precision of the calculation.

Based on this rectangular box assumption, the leaf area density of a crown can be expressed as

$\rho=L_{0} /\left[D^{2}(H-h)\right]$

where $\rho$ is the leaf area density of the crown $\left(\mathrm{m}^{2}\right.$ leaf $\mathrm{m}^{-3}$ space) and $L_{0}$ is the leaf area of the crown $\left(\mathrm{m}^{2}\right.$ leaf plant $\left.{ }^{-1}\right)$, expressed as $L_{0}=\mathrm{LAI}_{\mathrm{p}} \cdot D^{2}$. The $\mathrm{LAI}_{\mathrm{p}}$ is the local leaf area index of the individual crown, defined as the ratio between the leaf area of the crown and the ground area directly projected under the crown $\left(\mathrm{m}^{2}\right.$ leaf $\mathrm{m}^{-2}$ land). $D$ is the width of the crown (m), $H$ and $h$ are the heights (m) of the top and bottom of the crown, respectively.

\subsection{The algorithms of the model}

Solar radiation absorbed by leaves includes direct solar radiation (or solar beam), diffuse radiation from the sky (or simply called diffuse radiation), and scattered radiation generated by reflection and transmission of direct and diffuse radiation intercepted by leaves. Because the solar radiation

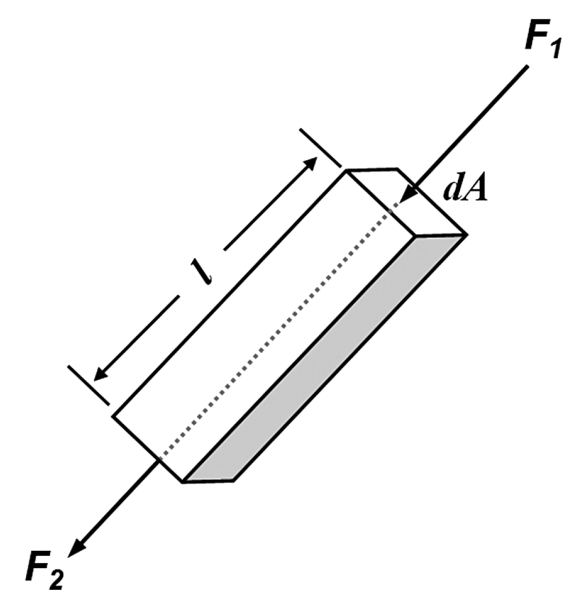

Figure 1. A general scheme and the related variables for interception of a light beam by a small column of canopy.

intercepted by sunlit leaves is much higher than that of the shaded leaves, an efficient way to up-scale photosynthesis from leaves to canopy is to divide the canopy into sunlit and shaded leaf classes (Norman, 1993). Therefore, we calculated the fractions of sunlit and shaded leaf classes of individual plants and the solar radiation absorbed for each class based on geometric optical relationships. Sunlit leaves and sunlit ground receive solar beam, diffuse radiation and scattered radiation, while shaded leaves and shaded ground receive only diffuse radiation and scattered radiation. The radiation on the ground is considered as the radiation available for mosses and lichens.

The following sections describe the detailed algorithms of the IPR model. In Sect. 2.2.1 we calculate the fractions of sunlit leaf area for the woody strata. This is the core of the IPR model. Diffuse radiation can be considered as isotropic beams from all the directions of the hemisphere, therefore the relative diffuse radiation can be calculated by integration of the sunlit fractions from different directions of the hemisphere. In Sect. 2.2.2 we calculate the fraction of sunlit leaf area and the relative diffuse radiation for the herb stratum. Since the herb stratum is assumed to be a uniform layer, the two-big-leaf method (Norman, 1982) can be used. After the interception of the woody and the herb strata, the fraction of sunlit area and the relative diffuse radiation on the ground can be determined (Sect. 2.2.3). In Sect. 2.2.4 we calculate the intensity of the direct and diffuse radiation intercepted by the woody and herb strata and the ground. In Sect. 2.2.5 we estimate the scattered radiation absorbed by the woody and the herb strata and the ground, and in Sect. 2.2.6 we sum up the direct, diffuse and scattered radiation for sunlit and shaded leaves of the woody and herb strata and the ground. 


\subsubsection{The fractions of sunlit leaf area and the relative diffuse radiation of the woody strata}

When a solar beam passes through a small column of plant canopy (Fig. 1), the sunlit leaf area can be estimated based on Norman (1982)

$\mathrm{d} L_{b}=F_{1} / K[1-\exp (-K \cdot \rho \cdot l)] \mathrm{d} A$,

where $\mathrm{d} L_{b}$ is the sunlit leaf area of the column $\left(\mathrm{m}^{2}\right.$ leaf), $\mathrm{d} A\left(\right.$ in $\left.\mathrm{m}^{2}\right)$ is the area of the column directly facing the beam, and $F_{1}$ is the solar beam before entering the column, expressed as the fraction of sunlit area on a surface. $l$ is the length of the column or the path length of light (m), and $\rho$ is the density of the leaf area of the column $\left(\mathrm{m}^{2}\right.$ leaf $\mathrm{m}^{-3}$ space), which can be calculated by Eq. (1). $K$ is the effective light extinction coefficient including the clumping effects:

$K=K_{0} \cdot \Omega$,

where $K_{0}$ is the light extinction coefficient when leaves are randomly distributed, and is a constant of 0.5 (Norman, 1982). $\Omega$ is the clumping index of the leaves in the crown (Chen and Black, 1992). The solar beam after the interception of the canopy can be determined based on the BeerLambert law

$F_{2}=F_{1} \cdot \exp (-K \cdot \rho \cdot l)$,

where $F_{2}$ is the solar beam after the interception of the canopy, expressed as the fraction of sunlit area on a surface. The solar beam intercepted by the column of canopy is

$\mathrm{d} F=F_{1}-F_{2}=F_{1}[1-\exp (-K \cdot \rho \cdot l)]$,

where $\mathrm{d} F$ is the solar beam intercepted by the column of canopy (in the same unit as $F_{1}$ and $F_{2}$ ). The shading effects of this column on subsequent objects can be expressed as

$f=F_{2} / F_{1}=\exp (-K \cdot \rho \cdot l)$,

where $f$ is the shading effect of the column on subsequent objects (in fractions ranged from 0 to $1: f=1$ for no shading, and $f=0$ for completely shaded).

For a plant at any moment, the total sunlit leaf area of the crown is the integration of $\mathrm{d} L_{b}$ for the entire crown. For rectangular box-shaped crowns, we can integrate numerically by dividing the crown into small slices parallel to the solar beam (Fig. 2a). The length of a slice or the light path length (equivalent to $l$ in Eq. 2) can be calculated analytically based on the height of the slice when the beam enters it (Fig. 2). There are two cases: when $\tan \theta \leq\left(H_{i}-h_{i}\right) / D_{i}$ (Fig. 2b),

$$
l_{z_{i}}= \begin{cases}0 & \left(z_{i} \leq h_{i} \text { or } z_{i} \geq H_{i}+D_{i} \cdot \tan \theta\right) \\ \left(z_{i}-h_{i}\right) / \sin \theta & \left(D_{i} \cdot \tan \theta+h_{i} \geq z_{i}>h_{i}\right) \\ D_{i} / \cos \theta & \left(H_{i} \geq z_{i}>D_{i} \cdot \tan \theta+h_{i}\right) \\ D_{i} / \cos \theta-\left(z_{i}-H_{i}\right) / \sin \theta & \left(H_{i}+D_{i} \cdot \tan \theta>z_{i}>H_{i}\right)\end{cases}
$$

(7a)

and when $\tan \theta>\left(H_{i}-h_{i}\right) / D_{i}$ (Fig. 2c),

$$
l_{z_{i}}= \begin{cases}0 & \left(z_{i} \leq h_{i} \quad \text { or } \quad z_{i} \geq H_{i}+D_{i} \cdot \tan \theta\right) \\ \left(z_{i}-h_{i}\right) / \sin \theta & \left(H_{i} \geq z_{i}>h_{i}\right) \\ \left(H_{i}-h_{i}\right) / \sin \theta & \left(h_{i}+D_{i} \cdot \tan \theta \geq z_{i}>H_{i}\right) \\ D_{i} / \cos \theta-\left(z_{i}-H_{i}\right) / \sin \theta & \left(H_{i}+D_{i} \cdot \tan \theta>z_{i}>h_{i}+D_{i} \cdot \tan \theta\right)\end{cases}
$$

where $l_{z i}$ is the path length of light going through a slice of crown of a plant of stratum $i$, with $z_{i}$ the height when the solar beam enters the crown slice, and $\mathrm{d} z_{i}$ the thickness of the crown slice in the vertical direction (m) (Fig. 2a). The cross-sectional area of the crown slice directly facing the solar beam can be expressed as

$\mathrm{d} A_{i}=D_{i} \cdot \cos \theta \cdot \mathrm{d} z_{i}$,

where $\mathrm{d} A_{i}$ is the area of the crown slice directly facing the solar beam (equivalent to $\mathrm{d} A$ in Eq. 2). $\theta$ is the elevation angle of the sun, $D_{i}$ is the width of the crown (m), and $H_{i}$ and $h_{i}$ are the heights of the top and bottom of the crown, respectively (m) (the subscript $i$ is for a plant of stratum $i$, or sometimes simply called plant $i$ ).

Some of the solar beam may be blocked by its neighbouring plants. For a stratum $j$, only the plants growing in a strip $D_{i}+D_{j}$ wide in the direction of the sun can shade plant $i$ (Fig. 3). Their shading effects can be estimated by dividing the land strip into $D_{j}$ by $D_{i}+D_{j}$ rectangles (except for the first rectangle close to plant $i$, whose width is defined by Eq. 14) to calculate the shading effects of the plants of stratum $j$ in each rectangle (Fig. 3):

$f_{i, j k}=\left(1-p_{j}\right)+p_{j} \cdot f_{0 i, j k}$,

where $f_{i, j k}$ is the average shading effect on a slice of crown of plant $i$ by the plants of stratum $j$ in rectangle $k$ shown in Fig. 3. It is the weighted sum of the solar beam from the gaps (no shading) and the solar beam going through the crowns of plants of stratum $j$. The $f_{0 i, j k}$ is the shading effect on a slice of crown of plant $i$ by a crown of plant $j$ in rectangle $k$. The $p_{j}$ is the probability of solar beam going through crowns of stratum $j$ in the rectangle. It is equal to the fraction of the land area covered by the crowns of the plants of the stratum (therefore it does not change with $i$ and $k$ ), and can be calculated as

$p_{j}=D_{j}^{2} \cdot d_{j}$,

where $d_{j}$ is the density of plants of stratum $j$ (plants $\mathrm{m}^{-2}$ ). Since the width of the rectangle is $D_{j}$, there is only one row of plants of stratum $j$ in a rectangle (i.e. the solar beam goes through no more than one crown of stratum $j$ in a rectangle). Therefore $f_{0 i, j k}$ can be calculated based on Eq. (6) for a slice of crown:

$f_{0 i, j k}=\exp \left(-K_{j} \cdot \rho_{j} \cdot l_{z j, k}\right)$, 


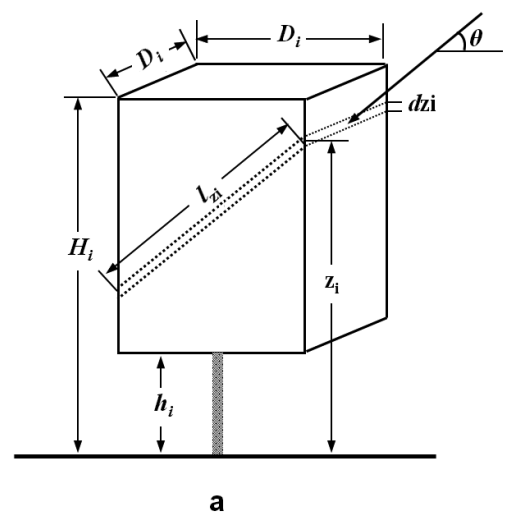

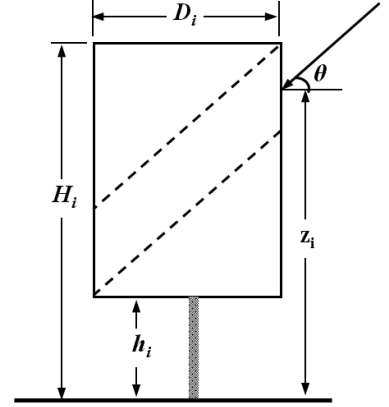

b

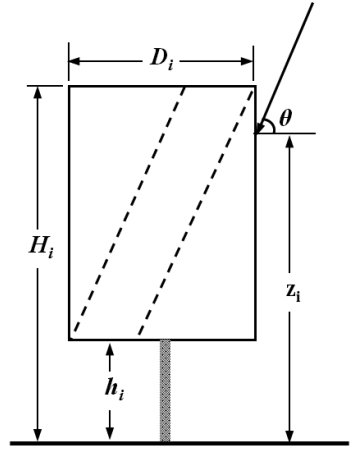

Figure 2. (a) Three-dimensional show for a light beam going through a slice of crown and the related variables. (b and c) Two-dimensional shows for the two cases when a light beam going through a crown.

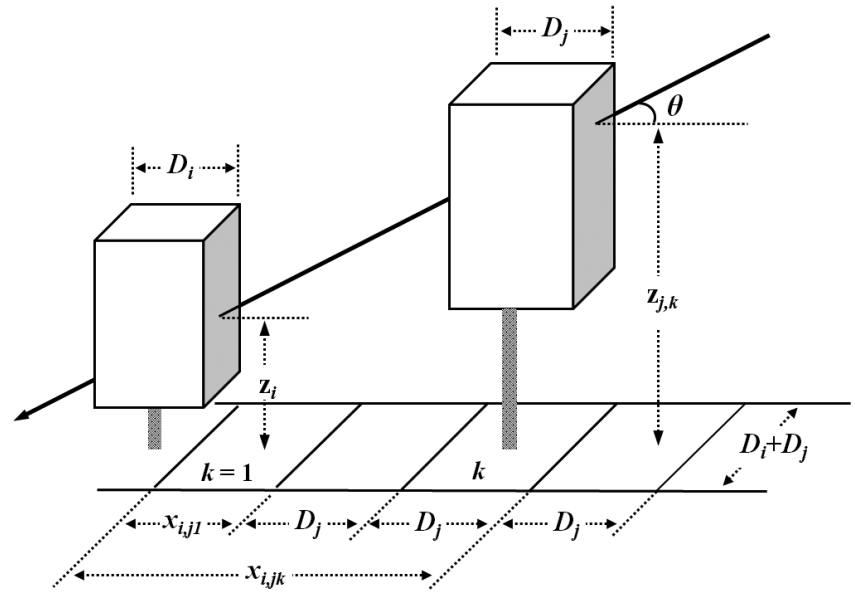

Figure 3. The scheme to calculate the shading effects of neighbouring plants in the model.

where $K_{j}$ is the effective light extinction coefficient for plant $j$, and $l_{z j, k}$ is calculated by Eq. (7) but for plants of stratum $j$ in rectangle $k$ corresponding to the height $\mathrm{z}_{j, k}$, which depends on the distance between the plant $i$ and plants of stratum $j$ in rectangle $k$ (Fig. 3):

$z_{j, k}=z_{i}+X_{i, j k} \cdot \tan \theta$,

where

$X_{i, j k}=X_{i, j 1}+(k-1) D_{j}$,

and

$X_{i, j 1}=\left[0.5\left(1-E_{\mathrm{T} j}\right)+E_{i j}\right] D_{j}$,

where $X_{i, j k}$ is the distance between the edge of the crown of plant $i$ and the farther edge of the crown of plant $j$ in rectangle $k$, and $X_{i, j 1}$ is the distance when $k$ equals 1 (the first rectangle near plant $i$, Fig. 3). $E_{i j}$ is the fraction of crown of plant $i$ overlapping vertically with the crown of plant $j$, and $E_{\mathrm{T} j}$ is the total fraction of the crowns of all the plant strata overlapping with a crown of stratum $j$ on average, calculated as

$E_{\mathrm{T} j}=\sum_{m=1}^{N} p_{m} \cdot E_{j m}$

where $N$ is the total number of woody strata of the plant community. $E_{j m}$ is the fraction of crown of plant $j$ overlapping vertically with the crown of plant $m$, defined as

$E_{j m}= \begin{cases}0 & \left(h_{m} \geq H_{j} \quad \text { or } \quad H_{m} \leq h_{j}\right) \\ {\left[\min \left(H_{j}, H_{m}\right)-h_{m}\right] /\left(H_{j}-h_{j}\right)} & \left(H_{j} \geq h_{m} \geq h_{j}\right) \\ {\left[H_{m}-\max \left(h_{j}, h_{m}\right)\right] /\left(H_{j}-h_{j}\right)} & \left(H_{j} \geq H_{m} \geq h_{j}\right)\end{cases}$

where $\min ()$ and $\max ()$ are operations to get the minimum and the maximum of the variables in the brackets, respectively. Since $E_{j m}$ is calculated relative to the crown height of plant $j$, it can be different from $E_{m j}$. Similar to $E_{m j}$, the $E_{i j}$ is the fraction of crown of plant $i$ overlapping vertically with the crown of plant $j$. Equation (14) was designed so that $X_{i, j 1}$ approximately equals $D_{j}$ (plant $j$ is very close to plant $i$ ) when the woody plants are dense $\left(E_{\mathrm{T} j} \approx 1\right)$; the $X_{i, j 1}$ is about $1.5 D_{j}$ when the woody plants are sparse $\left(E_{\mathrm{T} j} \approx 0\right)$; and the $X_{i, j 1}$ can be less than $0.5 D_{j}$ when stratum $j$ is completely above or below stratum $i\left(E_{i j}=0\right)$, especially when the woody plants are dense $\left(E_{\mathrm{T} j} \approx 1\right)$.

The shading effects on a slice of crown by all the neighbouring plants of stratum $j$ can be expressed as

$F_{1, i j}=\prod_{k=1}^{M_{j}} f_{i, j k}$,

where $\Pi$ is for multiplying all the terms for $k$ ranging from 1 to $M_{j}$. The shading effect on a slice of crown by all the 
neighbouring plants of all the strata can be expressed as

$F_{1, i}=\prod_{j=1}^{N} F_{1, i j}=\prod_{j=1}^{N} \prod_{k=1}^{M_{j}} f_{i, j k}$,

where $F_{1, i}$ is the shading effect on a slice of crown $i$ by all the neighbouring plants of all the strata, or the fraction of direction radiation available for entering the slice of the crown of plant $i$ after the interception of all its neighbouring plants. $M_{j}$ is the total number of rectangles considered in calculating the shading effects of stratum $j$ on plant $i$. It can be estimated by

$M_{j}=1+\left(X_{\max }-X_{i, j 1}-D_{i}\right) / D_{j}$

where $X_{\max }$ is a predefined maximum distance for shading effects (e.g. $100 \mathrm{~m}$ ) beyond which the shading effects of neighbouring plants are negligible. The total sunlit leaf area of the crown $i$ is the integration of Eq. (2) for all the slices of the crown (using Eq. 8) for $\mathrm{d} A$ and Eq. (18) for $F_{1}$ and integrating $\mathrm{d} z_{i}$ from $h_{i}$ to $\left.H_{i}+D_{i} \cdot \tan \theta\right)$ :

$$
\begin{aligned}
L_{b i}= & D_{i} \cdot \cos \theta / K i \int_{h_{i}}^{H_{i}+D_{i} \cdot \tan \theta}\left[1-\exp \left(-K_{i} \cdot \rho_{i} \cdot l_{z i}\right)\right] \\
& \cdot \prod_{j=1}^{N} \prod_{k=1}^{M_{j}} f_{i, j k} \cdot \mathrm{d} z_{i},
\end{aligned}
$$

where $L_{b i}$ is the total sunlit leaf area of the plant $i$ ( $\mathrm{m}^{2}$ leaf plant ${ }^{-1}$ ) when the elevation of the sun is $\theta$. The $K_{i}$ is the effective light extinction coefficient of plant $i$. The fraction of sunlit leaf area is

$$
f_{\text {sunlit }, i}=L_{b i} / L_{0 i}
$$

where $f_{\text {sunlit }, i}$ is the fraction of sunlit leaf area of a plant of stratum $i$. The $L_{0 i}\left(\mathrm{~m}^{2}\right.$ leaf plant $\left.{ }^{-1}\right)$ is the total leaf area of a plant of stratum $i$.

The fraction of the sunlit area on a horizontal surface after the interception of all the woody strata, $F_{2 \mathrm{w}}$, can be estimated by

$$
F_{2 \mathrm{w}}=1-\sum_{i=1}^{N} L_{b i} \cdot d_{i} \cdot K_{i} / \sin \theta
$$

$F_{2 \mathrm{w}}$ is the solar beam available for the herb stratum under the woody strata, expressed as the fraction of the sunlit area.

We assume that diffuse radiation is from the entire hemisphere and is in isotropic distribution, and that it is uniformly distributed within a crown. Thus, diffuse radiation intercepted by a crown can be calculated by integration of the sunlit fractions from different directions of the hemisphere. Since we assume that the intensity of diffuse radiation is the same in all directions, the integration will be the average of the sunlit fractions for the elevation angles from 0 to $\pi / 2$ :

$F_{\mathrm{d}, i}=2 / \pi \int_{0}^{\pi / 2} f_{\text {sunlit }, i}(\beta) \mathrm{d} \beta$,

where $F_{\mathrm{d}, i}$ is the relative diffuse radiation intercepted by the leaves of stratum $i$, expressed as the ratio to the diffuse radiation above the canopy of the plant community. The $f_{\text {sunlit, } i}(\beta)$ is the fraction of sunlit leaf area of the crown $i$ when the elevation angle of the beam is $\beta$, calculated by Eq. (21).

\subsubsection{The fraction of sunlit leaf area and the relative diffuse radiation of the herb stratum}

We assume that the herb stratum is distributed uniformly; therefore its fraction of sunlit leaf area can be calculated using the two-big-leaf method (Norman, 1982):

$$
\begin{aligned}
f_{\text {sunlit }, \mathrm{h}}= & F_{2 \mathrm{w}} \cdot \sin \theta /\left(K_{\mathrm{h}} \cdot \mathrm{LAI}_{\mathrm{h}}\right) \\
& {\left[1-\exp \left(-K_{\mathrm{h}} \cdot \mathrm{LAI}_{\mathrm{h}} / \sin \theta\right)\right], }
\end{aligned}
$$

where $f_{\text {sunlit,h }}$ is the fraction of the sunlit leaf area of the herb stratum, $\mathrm{LAI}_{\mathrm{h}}$ is the leaf area index of the herb stratum ( $\mathrm{m}^{2}$ leaf $\mathrm{m}^{-2}$ ground), $K_{\mathrm{h}}$ is the effective light extinction coefficient of the herb canopy, and $F_{2 \mathrm{w}}$ is the solar beam available after the interception of the woody strata, calculated by Eq. (22).

Similar to Eq. (23), the relative diffuse radiation intercepted by the herb stratum can be calculated as the average of the sunlit fractions for all the elevation angles from 0 to $\pi / 2$ :

$F_{\mathrm{d}, \mathrm{h}}=2 / \pi \int_{0}^{\pi / 2} f_{\text {sunlit,h }}(\beta) \mathrm{d} \beta$,

where $F_{\mathrm{d}, \mathrm{h}}$ is the relative diffuse radiation intercepted by leaves of the herb stratum, expressed as the ratio to the diffuse radiation above the canopy of the plant community.

\subsubsection{The fraction of sunlit area and the relative diffuse radiation on the ground}

Since the herb stratum is assumed a uniform canopy, its effects on the fraction of sunlit area on the ground can be expressed based on Beer's law (Monsi and Saeki, 1953):

$f_{\text {sunlit,g }}=F_{2 \mathrm{w}} \exp \left(-K_{\mathrm{h}} \cdot \mathrm{LAI}_{\mathrm{h}} / \sin \theta\right)$,

where $f_{\text {sunlit, }}$ is the fraction of sunlit area on the ground below the herb stratum. The exponential multiplier is the fraction intercepted by the herb stratum. 
Similar to Eq. (23), the relative diffuse radiation on the ground can be estimated by the average of $f_{\text {sunlit,g }}$ for all the elevation angles from 0 to $\pi / 2$ :

$$
F_{\mathrm{d}, \mathrm{g}}=2 / \pi \int_{0}^{\pi / 2} f_{\text {sunlit,g }}(\beta) \mathrm{d} \beta,
$$

where $F_{\mathrm{d}, \mathrm{g}}$ is the relative diffuse radiation on the ground, expressed as the ratio to the diffuse radiation above the canopy of the plant community.

\subsubsection{Direct and diffuse radiation intercepted by plants and the ground}

The direct radiation intercepted by sunlit leaves can be expressed as

$I_{b, i}=I_{b 0} \cdot K_{i} / \sin \theta$,

$I_{b, \mathrm{~h}}=I_{b 0} \cdot K_{\mathrm{h}} / \sin \theta$,

where $I_{b, i}$ and $I_{b, \mathrm{~h}}$ are the direct radiation intercepted by sunlit leaves of the woody plant $i$ and the herb stratum, respectively ( $\mathrm{W} \mathrm{m}^{-2}$ leaf), and $I_{b 0}$ is the direct radiation on a horizontal surface above the canopy of the plant community ( $\mathrm{W} \mathrm{m}^{-2}$ ground). The diffuse radiation intercepted by leaves can be calculated by

$I_{\mathrm{d}, i}=I_{\mathrm{d} 0} \cdot F_{\mathrm{d}, i}$,

$I_{\mathrm{d}, \mathrm{h}}=I_{\mathrm{d} 0} \cdot F_{\mathrm{d}, \mathrm{h}}$,

where $I_{\mathrm{d}, i}$ and $I_{\mathrm{d}, \mathrm{h}}$ are diffuse radiation intercepted by leaves of woody plant $i$ and the herb stratum, respectively ( $\mathrm{W} \mathrm{m}^{-2}$ leaf), and $I_{\mathrm{d} 0}$ is the diffuse radiation above the canopy of the plant community ( $\mathrm{W} \mathrm{m}^{-2}$ ground).

The direct radiation in the sunlit area on the ground equals $I_{b 0}$, and the diffuse radiation on the ground, $I_{\mathrm{d}, \mathrm{g}}$, is $I_{\mathrm{d} 0} \cdot F_{\mathrm{d}, \mathrm{g}}$ ( $F_{\mathrm{d}, \mathrm{g}}$ is calculated by Eq. 27$)$.

\subsubsection{Scattered radiation absorbed by the woody and herb strata and the ground}

The scattered radiation received by a woody plant includes scattered radiation generated by its own crown and the scattered radiation from surrounding plants - the latter part usually is very small so we omitted it in the model. The scattered radiation absorbed by a unit leaf area can be estimated based on Smolander and Stenberg (2005):

$I_{\mathrm{s} 1, i}=I_{\mathrm{s} 0, i} \cdot \alpha_{i} \cdot r_{i} /\left[1-\left(1-\alpha_{i}\right) r_{i}\right]$,

where $I_{\mathrm{s} 1, i}$ is the average scattered radiation absorbed by a unit leaf area of plant $i$ ( $\mathrm{W} \mathrm{m}^{-2}$ leaf), $\alpha_{i}$ is the light absorption coefficient of the leaves of plant $i$, the $I_{\mathrm{s} 0, i}$ is the average scattered radiation $\left(\mathrm{W} \mathrm{m}^{-2}\right.$ leaf, averaged for all the leaves in the crown) generated by reflection and transmission when direct and diffuse radiation are first intercepted by leaves of plant $i$ (zero-order scattering), and $r_{i}$ is the recollision probability of scattered radiation, which is assumed to remain constant in successive scattering (Smolander and Stenberg, 2005). $I_{\mathrm{s} 0, i}$ and $r_{i}$ can be estimated by

$$
\begin{aligned}
I_{\mathrm{s} 0, i} & =\left(1-\alpha_{i}\right)\left[I_{b, i} \cdot f_{\mathrm{sunlit}, i}+I_{\mathrm{d}, i}\right], \\
r_{i} & =1-\exp \left(-K_{i} \cdot \rho_{i} \cdot l_{\mathrm{a} i}\right),
\end{aligned}
$$

where $l_{\mathrm{a} i}$ is the average path length from a light source within the crown to outside of the crown, approximated as the average length from the centre of the crown to the six sides of the rectangular box:

$l_{\mathrm{a} i}=\left(H_{i}-h_{i}\right) / 6+D_{i} / 3$.

The scattered radiation received by the herb stratum includes the scattered radiation from the above woody strata and the scattered radiation generated within the herb canopy. On the top of the herb stratum, the scattered radiation from the above woody plants can be estimated as the difference between the scattered radiation generated by the woody plants and the amount of scattered radiation absorbed by the woody plants:

$I_{\mathrm{s} 1, \mathrm{~h}}=0.5 \sum_{i=1}^{M}\left(I_{\mathrm{s} 0, i}-I_{\mathrm{s} 1, i}\right) \cdot L_{0 i} \cdot d_{i}$,

where $I_{\mathrm{s} 1, \mathrm{~h}}$ is the average scattered radiation from the woody plants on a horizontal surface above the herb stratum ( $\mathrm{W} \mathrm{m}^{-2}$ ground). A factor of 0.5 was used in the equation because a horizontal surface below the woody crowns can only receive the downward scattered radiation (half of the total scattered radiation) from the woody strata. The average scattered radiation generated within the herb canopy can be estimated by

$I_{\mathrm{s} 0, \mathrm{~h}}=\left(1-\alpha_{\mathrm{h}}\right)\left[I_{b, \mathrm{~h}} \cdot f_{\text {sunlit,h}}+I_{\mathrm{d}, \mathrm{h}}\right]$,

where $I_{\mathrm{s} 0, \mathrm{~h}}$ is the average scattered radiation generated by reflection and transmission when direct and diffuse radiation are first intercepted by leaves of the herb stratum ( $\mathrm{W} \mathrm{m}^{-2}$ leaf), and $\alpha_{\mathrm{h}}$ is the light absorption coefficient of the herb stratum. The scattered radiation received by the herb leaves are the sum of the scattered radiation from above woody plants and the scattered radiation generated within the herb canopy. The former can be estimated similar to the estimation for diffuse radiation, while the latter can be estimated similarly to Eq. (32):

$I_{\mathrm{s}, \mathrm{h}}=\alpha_{\mathrm{h}} \cdot I_{\mathrm{s} 1 \mathrm{~h}} \cdot F_{\mathrm{d} 0, \mathrm{~h}}+I_{\mathrm{s} 0, \mathrm{~h}} \cdot \alpha_{\mathrm{h}} \cdot r_{\mathrm{h}} /\left[1-\left(1-\alpha_{\mathrm{h}}\right) r_{\mathrm{h}}\right]$,

where $I_{\mathrm{s}, \mathrm{h}}$ is the average scattered radiation absorbed by leaves of the herb stratum ( $\mathrm{W} \mathrm{m}^{-2}$ leaf), and $F_{\mathrm{d} 0, \mathrm{~h}}$ is the relative diffuse radiation for herb stratum when there is no woody stratum, calculated by Eq. (25) but with $F_{2 \mathrm{w}}=1$ for $f_{\text {sunlit,h }}$ estimation in Eq. (24). The $r_{\mathrm{h}}$ is the recollision probability of 
scattering radiation in the herb canopy, and can be estimated based on Smolander and Stenberg (2005):

$r_{\mathrm{h}}=0.88\left[1-\exp \left(-0.7 \cdot \mathrm{LAI}_{\mathrm{h}}^{0.75}\right)\right]$.

Similarly, the scattered radiation received on the ground, $I_{\mathrm{s}, \mathrm{g}}$, can be estimated by

$$
I_{\mathrm{s}, \mathrm{g}}=I_{\mathrm{s} 1, \mathrm{~h}} \cdot F_{\mathrm{d} 0, \mathrm{~g}}+0.5 I_{\mathrm{s} 0, \mathrm{~h}} \cdot \exp \left(-0.5 K_{\mathrm{h}} \cdot \mathrm{LAI}_{\mathrm{h}}\right)
$$

where $F_{\mathrm{d} 0, \mathrm{~g}}$ is the relative diffuse radiation on the ground when there is no woody stratum, calculated by Eq. (27) but with $F_{2 \mathrm{w}}=1$ for $f_{\text {sunlit, }}$ estimation in Eq. (26). The factor 0.5 is used because only half of the scattered radiation reaches the ground (the other half scatters to the sky from the top of the herb stratum).

\subsubsection{Solar radiation absorbed by sunlit and shaded leaves and the ground}

The sunlit leaves receive direct radiation from the sun, diffuse radiation from the sky, and scattered radiation, while the shaded leaves receive only diffuse radiation from the sky and scattered radiation. Therefore, the total solar radiation absorbed by sunlit and shaded leaves is

$$
\begin{aligned}
I_{\text {sunlit }, i} & =\alpha_{i}\left(I_{b, i}+I_{\mathrm{d}, i}\right)+I_{\mathrm{s} 1, i}, \\
I_{\text {shaded }, i} & =\alpha_{i} \cdot I_{\mathrm{d}, i}+I_{\mathrm{s} 1, i}, \\
I_{\text {sunlit, } \mathrm{h}} & =\alpha_{\mathrm{h}}\left(I_{b, \mathrm{~h}}+I_{\mathrm{d}, \mathrm{h}}\right)+I_{\mathrm{s}, \mathrm{h}}, \\
I_{\text {shaded }, \mathrm{h}} & =\alpha_{\mathrm{h}} \cdot I_{\mathrm{d}, \mathrm{h}}+I_{\mathrm{s}, \mathrm{h}},
\end{aligned}
$$

where $I_{\text {sunlit, } i}$ and $I_{\text {shaded, } i}$ are the total solar radiation ( $\mathrm{W} \mathrm{m}^{-2}$ leaf) absorbed by sunlit and shaded leaves of the woody stratum $i$, respectively, and $I_{\text {sunlit,h }}$ and $I_{\text {shaded,h }}$ are the total solar radiation $\left(\mathrm{W} \mathrm{m}^{-2}\right.$ leaf) absorbed by sunlit and shaded leaves of the herb stratum, respectively. For the ground, the total radiation absorbed on sunlit and shaded areas can be expressed as

$$
\begin{aligned}
I_{\text {sunlit,g }} & =\alpha_{\mathrm{g}}\left(I_{b 0}+I_{\mathrm{d}, \mathrm{g}}+I_{\mathrm{s}, \mathrm{g}}\right), \\
I_{\text {shaded }, \mathrm{g}} & =\alpha_{\mathrm{g}}\left(I_{\mathrm{d}, \mathrm{g}}+I_{\mathrm{s}, \mathrm{g}}\right)
\end{aligned}
$$

where $I_{\text {sunlit,g }}$ and $I_{\text {shaded,g }}$ are the total solar radiation ( $\mathrm{W} \mathrm{m}^{-2}$ ground) absorbed by sunlit and shaded areas of the ground, respectively. $\alpha_{g}$ is the light absorption coefficient of the ground (the albedo of the ground would be $1-\alpha_{g}$ ). The average solar radiation absorbed on the ground is

$$
\begin{aligned}
I_{\mathrm{avg}, \mathrm{g}} & =I_{\text {sunlit }, \mathrm{g}} \cdot f_{\text {sunlit, } \mathrm{g}}+I_{\text {shaded }, \mathrm{g}} \cdot\left(1-f_{\text {sunlit }, \mathrm{g}}\right) \\
& =\alpha_{\mathrm{g}}\left(I_{b 0} \cdot f_{\text {sunlit, } \mathrm{g}}+I_{\mathrm{d}, \mathrm{g}}+I_{\mathrm{s}, \mathrm{g}}\right)
\end{aligned}
$$

where $I_{\text {avg,g }}$ is the average solar radiation absorbed on the ground ( $\mathrm{W} \mathrm{m}^{-2}$ ground). Part of the solar radiation received on the ground will be reflected. In this study we did not consider the contribution of this reflected radiation to the leaves.

\subsection{Inputs and outputs of the model and calculation procedure}

The inputs for the IPR model include plant community features and the radiation conditions above the plant community. The plant community features include the number of woody plant strata $(N)$, the features of each woody stratum (plant density $\left(d_{i}\right)$, heights of the top and the bottom of the crown $\left(H_{i}\right.$, and $h_{i}$, respectively), crown width $\left(D_{i}\right)$, leaf area of the crown $\left(L_{0 i}\right)$, light absorption coefficient $\left(\alpha_{i}\right)$, and the clumping index of the leaves $\left(\Omega_{i}\right)$, and the features of the herb stratum (leaf area index $\left(\mathrm{LAI}_{\mathrm{h}}\right)$, light absorption coefficient $\left(\alpha_{h}\right)$, and the clumping index $\left.\left(\Omega_{h}\right)\right)$. The radiation conditions above the plant canopy include the elevation angle of the sun $(\theta)$, and direct and diffuse radiation on a horizontal surface above the plant community at the time $\left(I_{b 0}\right.$ and $I_{\mathrm{d} 0}$, respectively). There are two computing parameters: the maximum distance for shading effects $\left(X_{\max }\right)$ and the integration interval $\left(\mathrm{d} z_{i}\right)$. One hundred metres for $X_{\max }$ is large enough, and $\mathrm{d} z_{i}$ can be defined as $0.01\left(H_{i}-h_{i}\right)$.

The outputs of the model include the fractions of the sunlit leaf area for each woody stratum and the herb stratum, and the fraction of sunlit area on the ground, the radiation of the sunlit and shaded leaf classes of each woody stratum and the herb stratum, the radiation on sunlit and shaded areas on the ground, and the average radiation on the ground. The code for calculating the diurnal variations of the radiation conditions and a user's manual of the model can be found in the Supplement.

The IPR model first calculates the fraction of the sunlit leaf area for each elevation angle from 0 to $\pi / 2$ with a small step (e.g. $\pi / 36$, or 18 steps). The relative diffuse radiation for each stratum and on the ground can be calculated by numerically integrating the above results with the elevation angle. The fraction of sunlit leaf area of each stratum at any time can be interpolated from the above calculation based on the elevation of the sun at the time. Then the solar radiation absorbed by a plant of each stratum and on the ground can be calculated based on the direct and diffuse radiation above the plant community at the time.

\subsection{Testing of the model}

\subsubsection{Comparing with the fraction of sunlit leaf area calculated by the random approach}

In IPR, the calculation of solar radiation for herb stratum is based on Norman (1982), which has been tested and used widely. Diffuse radiation is calculated in a similar way as for direct radiation but the beams are from the entire hemisphere. Therefore the core of the IPR model is the calculation of the fraction of sunlit leaf area of individual plants of woody strata. Detailed field measurements are not available for model test. However, we can test the model by numerically tracing light beams to calculate sunlit leaf area 


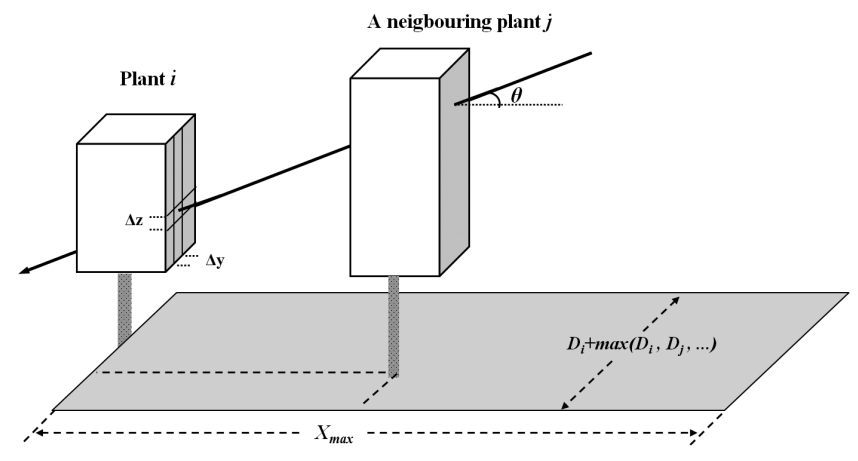

Figure 4. The scheme of the random approach for numerically calculating sunlit leaf area and the shading effects of the neighbouring plants. $\max \left(D_{i}, D_{j}, \ldots\right)$ is for the maximum of the crown width of all the plant strata in the plant community.

assuming that plants are randomly distributed (abbreviated as the random approach). The following is the description of the random approach.

1. Defining an area. This is the area in which neighbouring plants can cast shadows onto a plant of stratum $i$ located at the middle of one end of the area or the strip shown in light grey in Fig. 4. The width of the strip is the crown width $D_{i}$ plus the maximum of crown width of all the strata in the plant community. The length of the strip $\left(X_{\max }\right)$ was set as $100 \mathrm{~m}$ (the shading effect on plant $i$ is ignorable for plants beyond this distance).

2. Determining the number of woody plants in the strip. The number of woody plants for each stratum in the strip can be determined based on the area of the strip and the density of each woody stratum.

3. Putting the woody plants randomly in the strip. First we generate a pair of random numbers as the possible location of a plant in the strip. Then we check its distance from the existing plants in the strip to make sure that the crown of this plant does not overlap with the existing plants. If the distance was less than the minimum distance to one of the existing plants, we re-generated a pair of random numbers for a new location and checked again until the distance requirement was satisfied. Plants of two woody strata can distribute independently if one stratum is completely over or below the other stratum.

4. Calculating sunlit leaf area numerically. We divide the crown of plant $i$ into small cells (Fig. 4). A light beam going through a cell may go through crowns of its neighbouring plants. Based on the locations and crown sizes of the plants, we can geometrically determine whether a neighbouring plant can intercept the light beam (Fig. 4). If so, its shading effects can be calculated based on Eq. (7) (the height $z_{i}$ in Eq. (7) can be determined according to the height of the cell, the

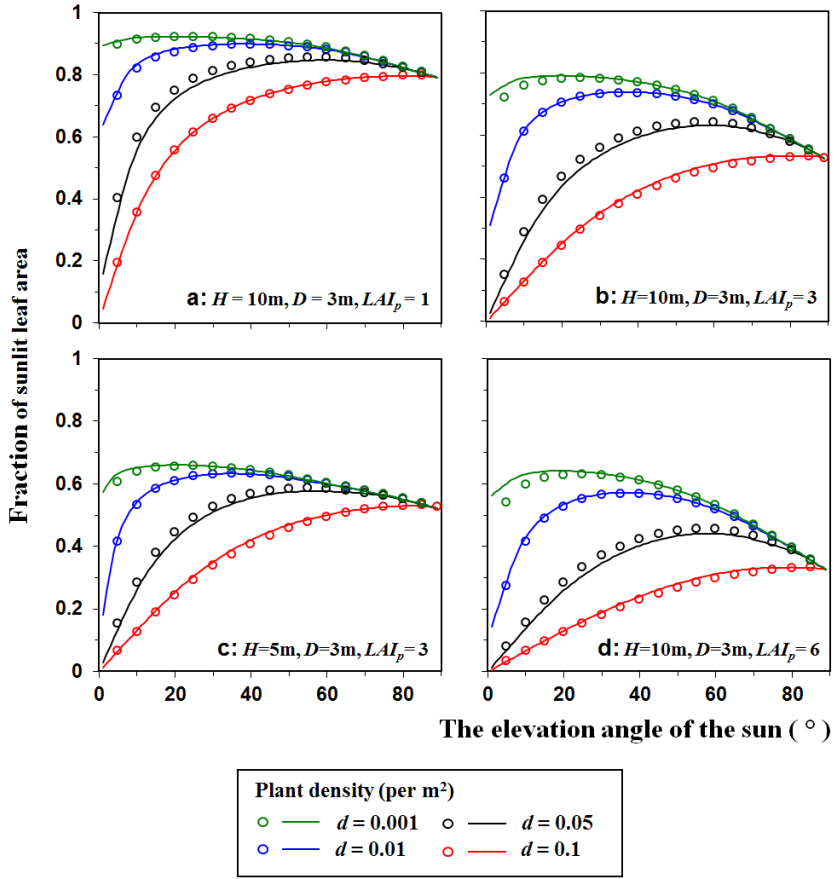

Figure 5. Comparisons of the calculated fractions of sunlit leaf area between the IPR model (curves) and the average of the random approach (circles) for one-stratum plant communities of different heights $(H)$, crown width $(D)$, local leaf area indices $\left(\mathrm{LAI}_{\mathrm{p}}\right)$ and plant densities $(d)$. Different colours correspond to different plant densities shown in the legend. The top height of crown, crown width and local leaf area indices are shown in the panels. The bottom height of the crown $(h)$ is $0 \mathrm{~m}$. The circles for $d=0.1$ plants $\mathrm{m}^{-2}$ were calculated assuming that plants are distributed regularly because plants cannot be distributed randomly without overlapping in such a dense plant community.

distance between the two plants, and the elevation angle of the beam). The size of the cell was defined as $\Delta z=0.01\left(H_{i}-h_{i}\right)$ and $\Delta y=0.01 D_{i}$. The sunlit leaf area of the crown is the total of the sunlit area of all the cells.

5. Repeating steps $2-4$ until the average fraction of sunlit leaf area is stable. The calculated fraction of sunlit leaf area under each case of the random distribution of neighbouring plants is different. But their average becomes very stable after 300 random cases (the variation is less than 0.001 for the fraction of sunlit leaf area). Therefore, we ran 300 random distribution cases for each test and then used the average to compare with the result of the IPR model.

\subsubsection{Sensitivity tests}

When a plant community has two or more strata and plant density is high, the random approach cannot distribute the plants randomly without overlapping. Thus we cannot use 


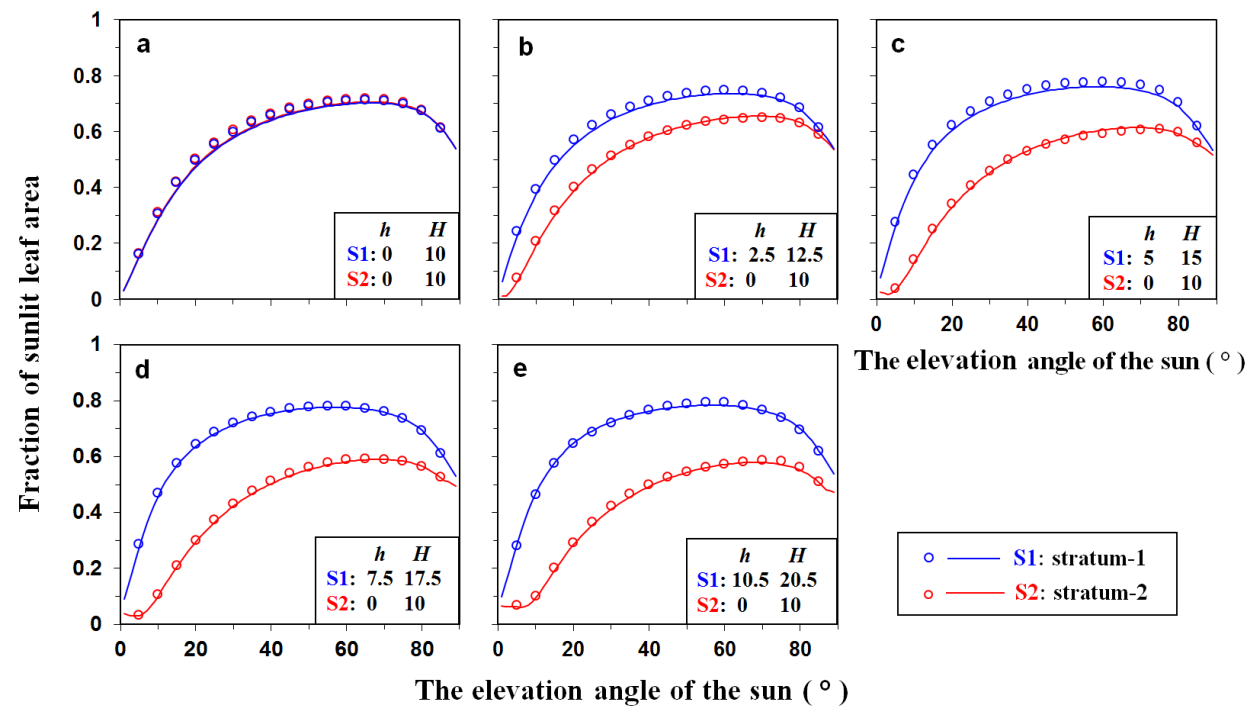

Figure 6. Comparisons of the calculated fractions of sunlit leaf area between the IPR model (curves) and the random approach (circles) for two-stratum plant communities of different heights (stratum-1 is shifted higher and higher). Blue and red colours are for stratum-1 (S1) and stratum-2 (S2), respectively. The top and bottom heights of the crowns ( $h$ and $H$ ) were shown in each panel. Other parameters are the same (crown width $D=1 \mathrm{~m}$, local leaf area index $\mathrm{LAI}_{\mathrm{p}}=3$, plant density $d=0.2$ plants $\mathrm{m}^{-2}$ ).

the random approach to test the IPR model in such cases. Instead we tested the sensitivity of the model to plant densities to show its consistency under different plant densities. We also compared the IPR results with that of the two-big-leaf method with different plant densities for one-stratum communities and for two-stratum plant communities when the crowns are of the same height and when the crowns of one stratum are completely above the other. Such comparisons not only can test the IPR model when the canopy almost completely covers the ground, they also show the errors of the two-big-leaf method when the crowns are sparse.

\section{Results and analyses}

\subsection{Comparing with the fractions of sunlit leaf area calculated using the random approach}

\subsubsection{One-stratum plant communities}

Figure 5 shows comparisons of the fraction of sunlit leaf area $\left(f_{\text {sunlit }}\right)$ calculated by IPR and the average of the random approach under different plant density, local leaf area index of the individual crown $\left(\mathrm{LAI}_{\mathrm{p}}\right)$, and the elevation angle of the sun $(\theta) . f_{\text {sunlit }}$ calculated by the IPR model is very close to the average of the random approach in all the cases. $f_{\text {sunlit }}$ increases with the decrease in plant density because of the decrease in shading effects by surrounding plants. For the same reason, the effects of plant density are stronger when $\theta$ is low. The $f_{\text {sunlit }}$ of different plant density converges with increase in $\theta$, and reaches the same value when the light is straight down, as $f_{\text {sunlit }}$ in that case only depends on LAI . The $f_{\text {sunlit }}$ decreases with the increase in $\mathrm{LAI}_{\mathrm{p}}$ for a given $\theta$ (Fig. 5a-c). If we reduce the plant height by half without changing $\mathrm{LAI}_{\mathrm{p}}$, then $f_{\text {sunlit }}$ decreases significantly (almost equal to doubling $\mathrm{LAI}_{\mathrm{p}}$ ) when $\theta$ is low (compare Fig. $5 \mathrm{~b}$ and d). This is because reducing crown height without changing $\mathrm{LAI}_{\mathrm{p}}$ increases the leaf area density or increases optical thickness when $\theta$ is low. The effect of height is not significant when $\theta$ is high.

\subsubsection{Two-stratum plant communities}

For two-stratum plant communities, the fractions of sunlit leaf area calculated by IPR are very close to the averages of the random approach as well for different heights (Fig. 6). When the heights of the two strata are the same, the fractions of the sunlit leaf area for the two strata are the same (Fig. 6a), and are almost the same as the results using onestratum but double the plant density (the curve is not shown since it overlaps other curves in Fig. 6a). When one stratum becomes higher, the $f_{\text {sunlit }}$ of the upper stratum increases and the $f_{\text {sunlit }}$ of the lower stratum decreases because of the increased shading effects of the upper stratum on the lower one (see gradual changes from Fig. 6a to e). The $f_{\text {sunlit }}$ of the lower stratum is close to that of the upper stratum when $\theta$ is near $90^{\circ}$ as the upper stratum has little shading effect on the low stratum in that case.

Figure 7 shows comparisons under different combinations of crown heights, plant density, crown width and leaf area. $f_{\text {sunlit }}$ calculated by the IPR model is very close to the average of the random approach in the different cases. Reducing the density of the lower stratum does not much affect the taller stratum. However, reducing the density of the taller 


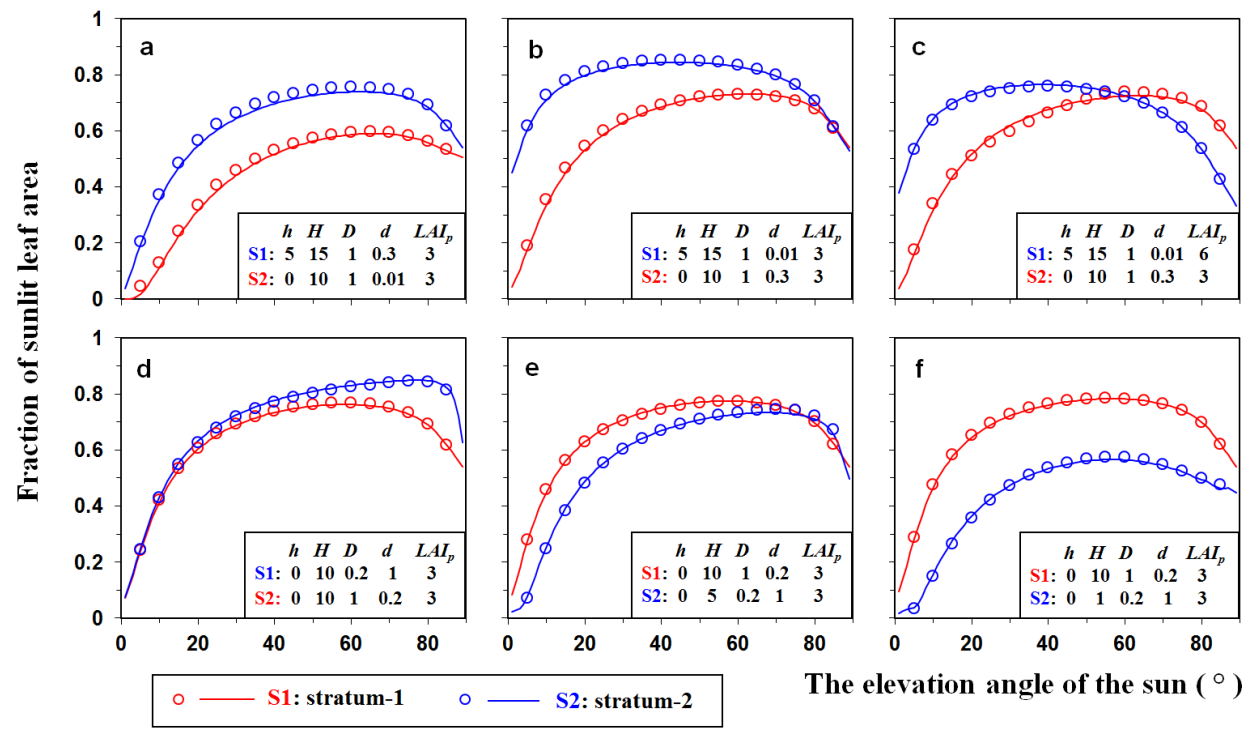

Figure 7. Comparisons of the calculated fractions of sunlit leaf area between the IPR model (curves) and the random approach (circles) for two-stratum plant communities. Red and blue are for stratum-1 (S1) and stratum-2 (S2), respectively. Their crown parameters are listed in each panel: $H$ and $h$ are the heights of the top and bottom of the crown, respectively $(\mathrm{m}), D$ is the width of the crown (m), $d$ is the density of plants (plants $\mathrm{m}^{-2}$ ), and $\mathrm{LAI}_{\mathrm{p}}$ is the local leaf area index $\left(\mathrm{m}^{2}\right.$ leaf $\mathrm{m}^{-2}$ ground).

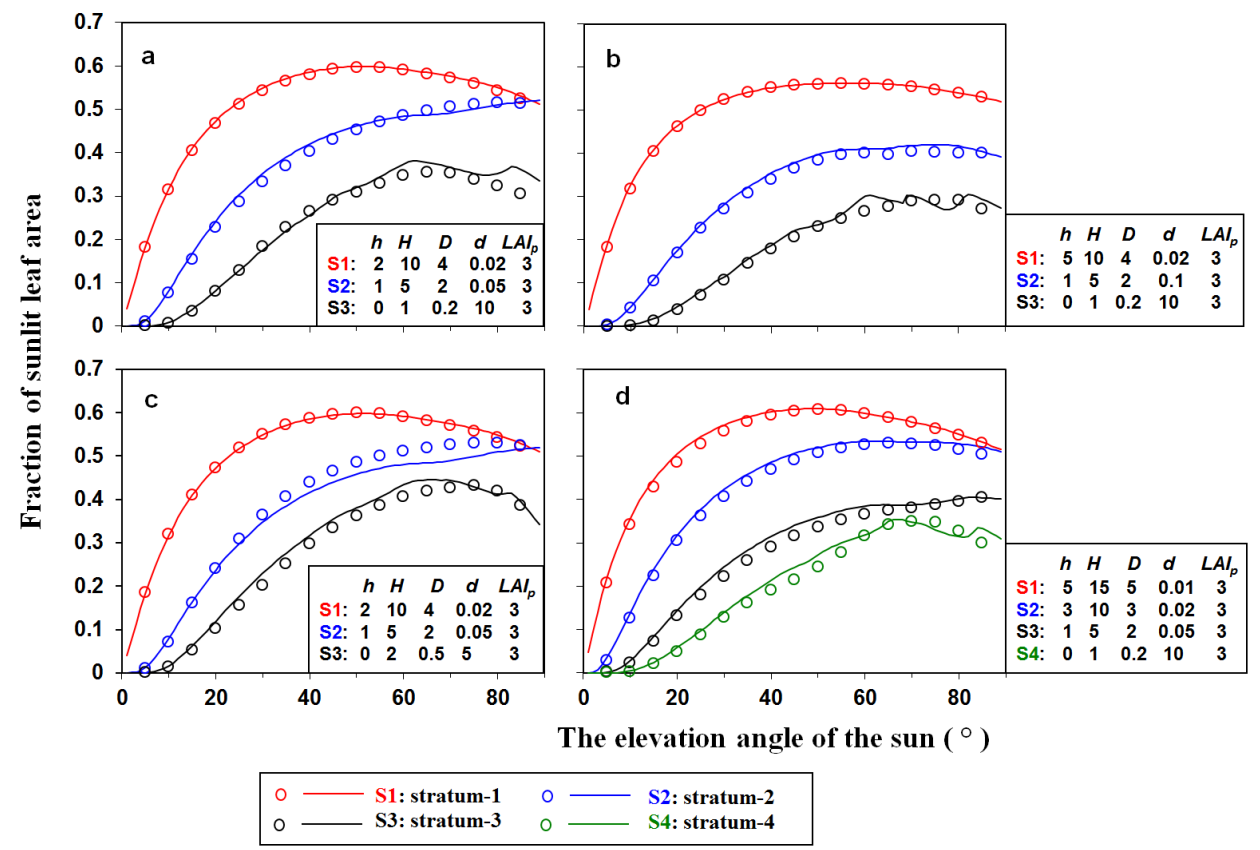

Figure 8. Comparisons of the calculated fractions of sunlit leaf area between the IPR model (curves) and the random approach (circles) for (a-c) three-stratum plant communities and for (d) four-stratum plant communities. Different colours are for different strata. The crown parameters are listed within or beside each panel: $H$ and $h$ are the heights of the top and bottom of the crown, respectively (m), $D$ is the width of the crown (m), $d$ is the density of plants (plants $\mathrm{m}^{-2}$ ), and LAI $\mathrm{p}$ is the local leaf area index ( $\mathrm{m}^{2}$ leaf $\mathrm{m}^{-2} \mathrm{ground}_{\text {). }}$

stratum increases $f_{\text {sunlit }}$ for both strata (Fig. 7a and b). Increasing $\mathrm{LAI}_{\mathrm{p}}$ (no change in crown width) of the taller stratum reduces its $f_{\text {sunlit, }}$ especially when $\theta$ is high, but that does not much affect the $f_{\text {sunlit }}$ of the lower stratum, because its light mainly comes from the gaps of the taller stratum (Fig. $7 \mathrm{~b}$ and c). Reducing crown width (no change in $\mathrm{LAI}_{\mathrm{p}}$ ) can slightly increase $f_{\text {sunlit }}$ when $\theta$ is low, because the path length of light going through the crown becomes shorter 

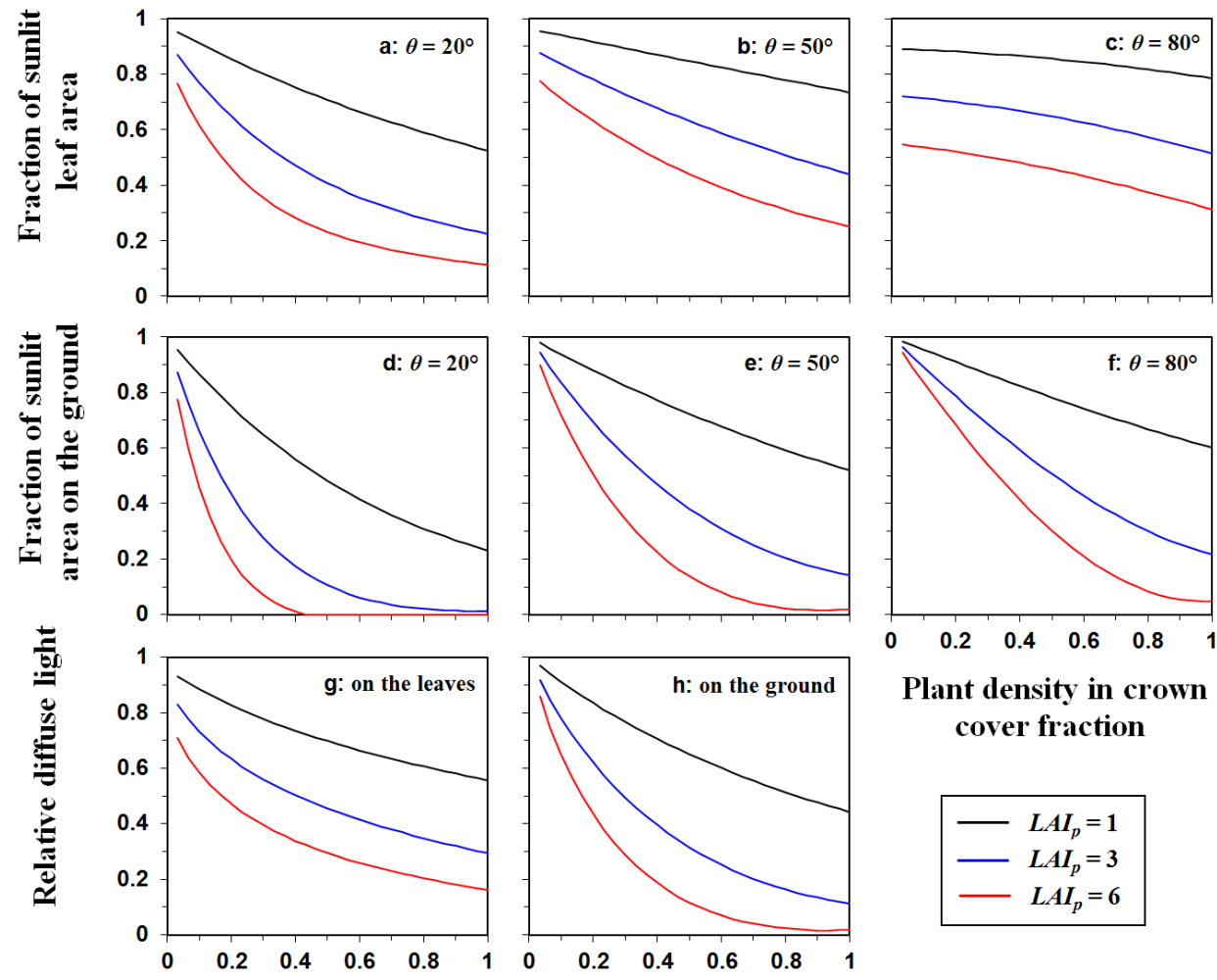

Plant density in crown cover fraction

Plant density in crown cover fraction

Figure 9. The sensitivity of the fractions of sunlit area on the leaves and on the ground to plant density and the local leaf area index of the plant. Plant density is expressed as the fraction of land covered by crowns, calculated by $D^{2} d$ ( $D$ is the width of the crown and $d$ is the number of plants per square metre). The relative diffuse light is the ratio to the diffuse light on a horizontal surface above the canopy. The plant communities are composed of only one stratum $(h=0 \mathrm{~m}, H=10 \mathrm{~m}, D=1 \mathrm{~m})$.

(Fig. 7d). Figure 7d-f show again that the relative heights of the plants have a significant impact on light competition among plant strata.

\subsubsection{Plant communities with three or more strata}

The fraction of sunlit leaf area calculated by the IPR model is very similar to the average of the random approach for plant communities with three and four strata as well (Fig. 8). The relative heights are the major factor affecting $f_{\text {sunlit }}$ for each stratum (the three strata are overlapped vertically in Fig. 8a and $\mathrm{c}$ while they are not overlapped in Fig. $8 \mathrm{~b}$ ). $f_{\text {sunlit }}$ of the low stratum also depends on its own crown features and its plant density (compare stratum 3 in Fig. 8a with c).

\subsection{Sensitivity analyses}

\subsubsection{One-stratum plant communities}

The fractions of sunlit leaf area and sunlit area on the ground are very sensitive to plant density and local leaf area index of the plants (Fig. 9). $f_{\text {sunlit }}$ decreases with increase in plant density (all curves show declining patterns in Fig. 9a to c), but the decrease becomes smaller when $\theta$ is higher (compare curves with the same colour from Fig. 9a to c), because the shading effect of neighbouring plants is less severe when $\theta$ is higher $\left(f_{\text {sunlit }}\right.$ is independent of plant density when light is straight down since there is no shading among plants at all in that case). The fraction of sunlit area on the ground decreases quickly with increase in plant density. Similarly to the changes in $f_{\text {sunlit }}$, the fraction of sunlit area on the ground increases with increase in $\theta$ due to decrease of the shading effects (compare curves with the same colour from Fig. 9d to f). Increase in $\mathrm{LAI}_{\mathrm{p}}$ reduces $f_{\text {sunlit }}$, and also significantly reduces the fraction of sunlit area on the ground. Since the relative diffuse radiation (intercepted by leaves or on the ground, see Fig. 9g and $h$ ) is an integration of all the elevation angles, its sensitivity to plant density is similar to that of the sunlit fraction (intercepted by leaves or on the ground) when $\theta$ is around $45^{\circ}$.

Crown width affects $f_{\text {sunlit }}$ mainly when plants are sparse and the elevation angle of the sun is low $\left(\mathrm{LAI}_{\mathrm{p}}\right.$ was kept constant in the tests) (Fig. 10). This is because the solar beam goes through a longer path in a crown when the crown is wider and $\theta$ is lower. This effect becomes relatively small when plants are dense. The fraction of sunlit area on the ground is more dependent on the fraction of ground covered 


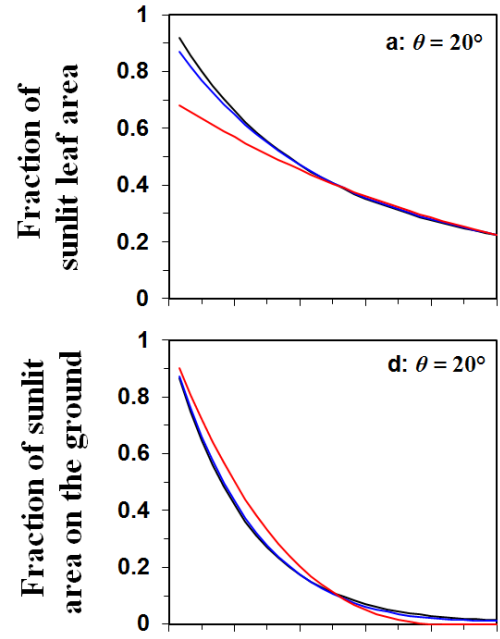

晋
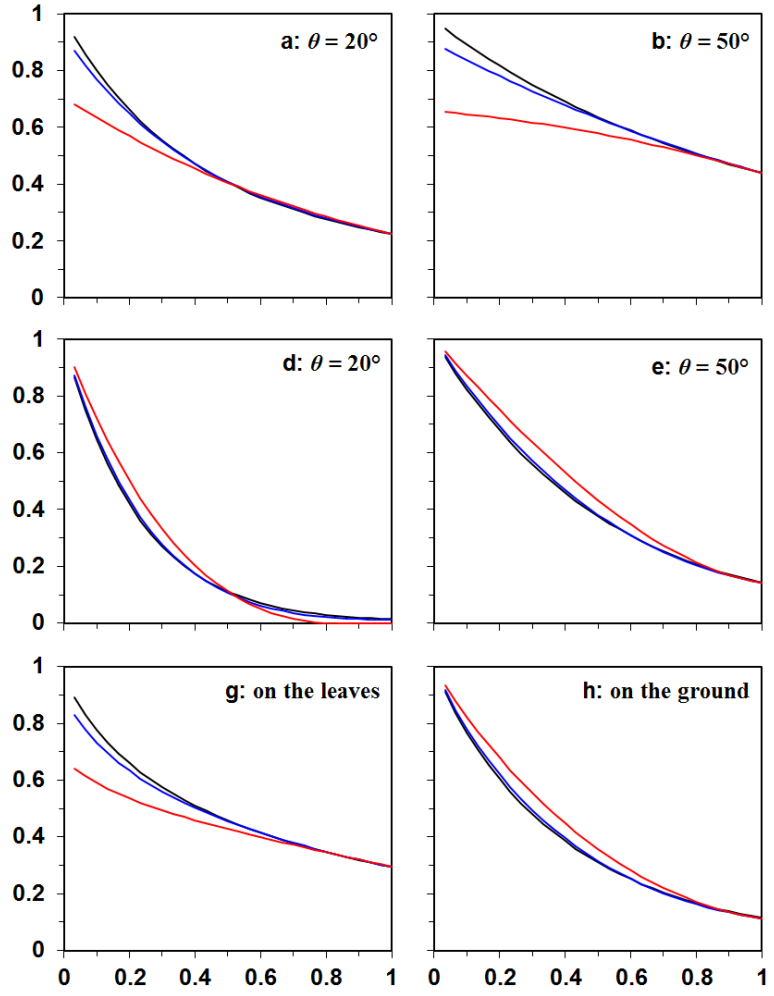
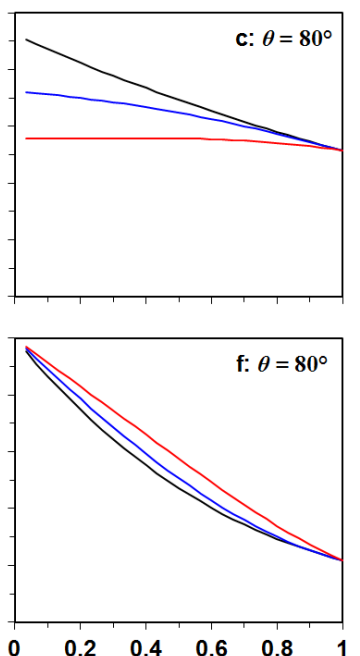

Plant density in crown cover fraction

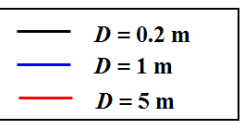

Plant density in crown cover fraction

Figure 10. The sensitivity of the fractions of sunlit area (on the leaves and on the ground) and relative diffuse radiation to plant density and crown width. Plant density is expressed as crown cover fractions, calculated by $D^{2} d(D$ is the width of the crown and $d$ is the number of plants per square metre). The relative diffuse light is the ratio to the diffuse light on a horizontal surface above the canopy. The plant communities are composed of only one stratum $\left(h=0 \mathrm{~m}, H=10 \mathrm{~m}, \mathrm{LAI}_{\mathrm{p}}=3\right)$.

by crowns (calculated by $D^{2} \cdot d$ ) rather than crown width. The effect of crown height on the fraction of sunlit area on the ground is very small (assuming no changes in $\mathrm{LAI}_{\mathrm{p}}$, plant density or crown width. Figures are not shown). However, crown heights are very important for light competition among plant strata, as discussed in the previous section and as will be emphasized in the following section as well.

\subsubsection{Two-stratum plant communities}

Figure 11 shows the sensitivity of the fractions of sunlit area and relative diffuse radiation (on the leaves and on the ground) to plant density for two-stratum plant communities. Increasing the density of the taller stratum has stronger impacts than increasing the density of the lower stratum, especially when $\theta$ is low (comparing the black curve with the blue curve in each panel in Fig. 11a to f). Even when the total fractions of land covered by the two strata do not change, increasing the density of the taller stratum (decreasing the density of the lower stratum at the same time) always results in a decrease of $f_{\text {sunlit }}$ for both strata (green curves in Fig. 11a to $\mathrm{f})$. The $f_{\text {sunlit }}$ of the lower stratum is more sensitive than that of the taller stratum to changes in plant density of either one or both strata when $\theta$ is not very high (comparing the curves of the same colour (excepting the green curves) between Fig. 11a and d, b and e, c and f, respectively). The $f_{\text {sunlit }}$ of the lower stratum increases with the increase in $\theta$, because more light can reach the lower stratum through the gaps of the taller stratum (compare curves of the same colour from Fig. 11d to f).

The fraction of sunlit area on the ground decreases with the increase in the density of either stratum, and is more related with the total plant density of the two strata (Fig. 11g to i). The fraction of sunlit area on the ground is higher when $\theta$ is higher, since more light can reach the ground from gaps among plants. Similar to $f_{\text {sunlit }}$, the relative diffuse radiation intercepted by the lower stratum is more sensitive than that of the taller stratum to plant density of either stratum (Fig. 11j and $\mathrm{k}$ ). The relative diffuse radiation on the ground depends on the total plant density of the two strata (Fig. 111).

These sensitivity tests show that the IPR model can calculate the solar radiation intercepted by leaves and the ground consistently from very sparse to continuous plant communities. 


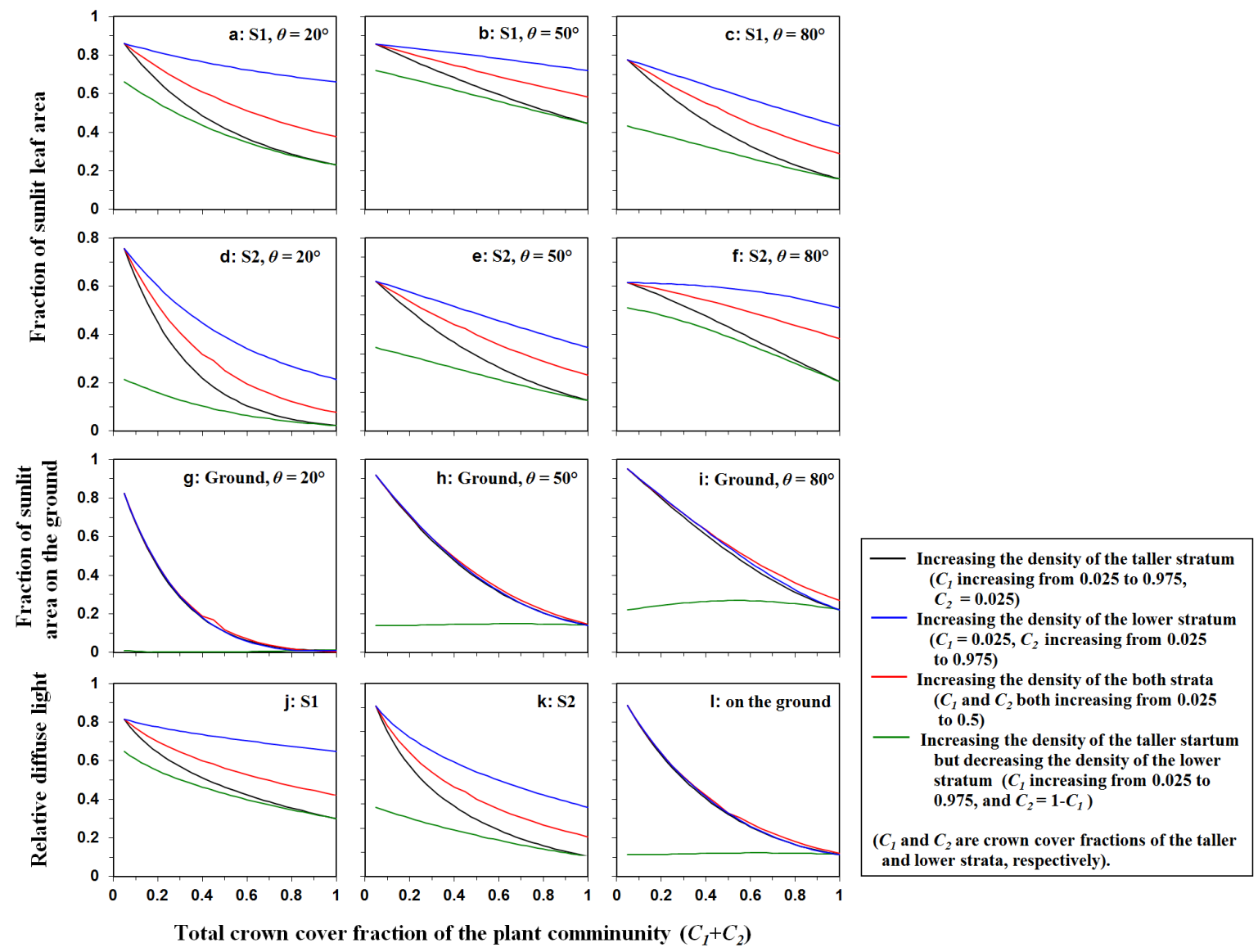

Figure 11. The sensitivity of the fractions of sunlit area (on the leaves and on the ground) and relative diffuse radiation to plant density for two-stratum plant communities (the taller stratum (S1): $h_{1}=2 \mathrm{~m}, H_{1}=10 \mathrm{~m}, D_{1}=1 \mathrm{~m}, \mathrm{LAI}_{\mathrm{p} 1}=3$; the lower stratum (S2): $h_{2}=0 \mathrm{~m}$, $\left.H_{2}=5 \mathrm{~m}, D_{2}=1 \mathrm{~m}, \mathrm{LAI}_{\mathrm{p} 2}=3\right)$. Plant density is expressed as crown cover fractions for both strata $\left(C_{1}\right.$ and $\left.C_{2}\right)$, calculated by $D_{1}^{2} d_{1}$ and $D_{2}^{2} d_{2}$, respectively ( $D_{1}$ and $D_{2}$ is the widths of the crowns of the two strata, respectively, and $d_{1}$ and $d_{2}$ are the numbers of plants per square metre for the two strata, respectively). The relative diffuse light is the ratio to the diffuse light on a horizontal surface above the canopy.

\subsubsection{Comparing with results of the two-big-leaf method}

Figure 12 shows comparisons of the calculated fractions of sunlit leaf area between the IPR model and the two-big-leaf method (the two-big-leaf method assumes that the canopy covers the ground uniformly; the leaf area index was calculated as $D^{2} \cdot d \cdot \mathrm{LAI}_{\mathrm{p}}$ ). The two-big-leaf method significantly overestimates $f_{\text {sunlit }}$ when plants are sparse and $\theta$ is high. Another difference is their variation patterns: $f_{\text {sunlit }}$ calculated by the two-big-leaf method always increases with the increase in $\theta$, whereas $f_{\text {sunlit }}$ calculated by IPR usually increases at the beginning, and then decreases gradually with the increase in $\theta$, especially when plants are sparse. When $\theta$ is very low, increasing $\theta$ significantly reduces the shading of neighbouring plants, thus $f_{\text {sunlit }}$ increases rapidly. When $\theta$ is high, however, increasing $\theta$ results in more light reaching the ground from the gaps among the crowns, thus $f_{\text {sunlit }}$ decreases with $\theta$. The two-big-leaf method cannot capture this variation pattern. The difference between IPR and the two-big-leaf method becomes smaller when the plant community is denser (or the gaps among crowns are smaller), especially when $\theta$ is low. When the canopy completely covers the ground, $f_{\text {sunlit }}$ calculated by the IPR model is almost the same as that of the two-big-leaf method. The differences are less than 0.002 for one-stratum plant communities and for two-stratum communities with crowns of one stratum completely above the other; and the differences are less than 0.02 for two-stratum communities when the heights of the crowns are the same (figures are not shown since the difference is too small).

\section{Discussion and conclusions}

Motivated to understand and predict the dynamics of vegetation in northern high latitudes under climate warming, we developed an approach to calculate solar radiation absorbed by individual plants in sparse heterogeneous woody plant 


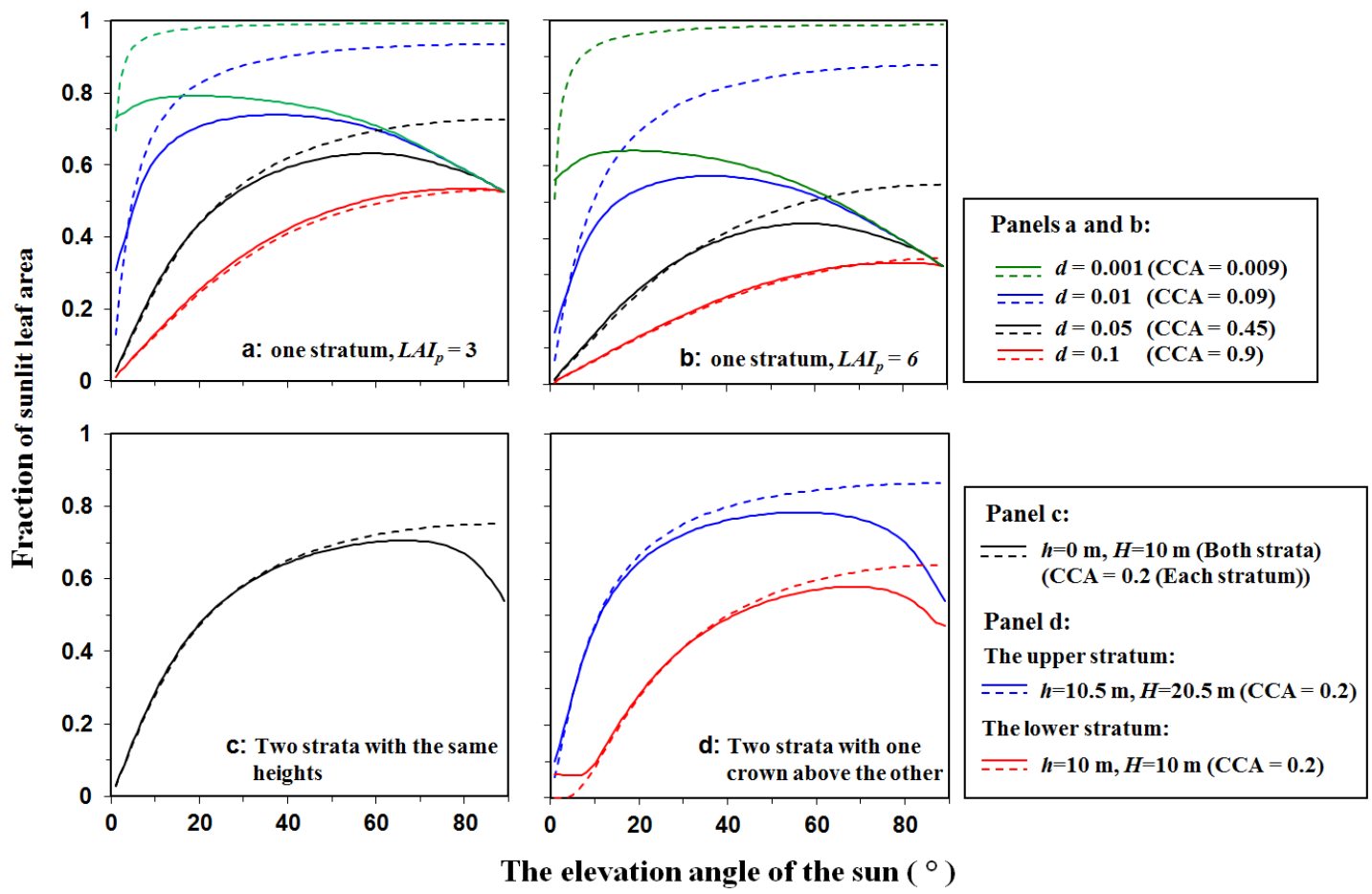

Figure 12. Comparisons of the calculated sunlit leaf area fractions between the IPR model (solid curves) and the two-big-leaf method (dashed curves). Panels (a) and (b) are for one-stratum plant communities with different local leaf area index ( $\left.\mathrm{LAI}_{\mathrm{p}}\right)$ and plant densities $(d)$ (shown in each panel and the legend). The other parameters are the same: the bottom height of the crown $h=0 \mathrm{~m}$, the top height of the crown $H=10 \mathrm{~m}$, and crown width $D=3 \mathrm{~m}$. The fraction of crown covered area (CCA) was calculated by $D^{2} \cdot d$ and is also shown in the legend. Panels (c) and (d) are for two-stratum plant communities with the same crown heights and one crown above the other, respectively (crown heights and CCA are shown in the legend). The other crown parameters are the same: crown width $D=1 \mathrm{~m}$, local leaf area index LAI $=3$, and plant density $d=0.2$ plants $\mathrm{m}^{-2}$. For the two-big-leaf method, the leaf area index of a stratum was calculated as $D^{2} \cdot d \cdot \mathrm{LAI}_{\mathrm{p}}$.

communities based on geometrical optical relationships. The core of the calculation is to determine the fraction of sunlit leaf area of sparse woody plants. We tested the model by comparing with the numerical simulations assuming plants are distributed randomly. The results show that the IPR calculated fractions of sunlit leaf area of the individual plants are very close to the averages of random distributions of the plants, and the results are consistent for different heights, crown width, leaf area, plant density, and under different elevation angles of the sun.

Comparing to the two-big-leaf method (e.g. Sellers et al., 1992; Norman, 1980; Wang and Leuning, 1998), the IPR model can be used for continuous and discontinuous plant canopies. IPR gives almost the same results as the two-bigleaf method when the canopy is continuous. When crowns are sparse, the IPR model can consider the light directly reaching the ground from the gaps of the crowns, and therefore is more accurate than the two-big-leaf method. In addition, the IPR model can be used for plant communities composed of several different woody strata, and each plant stratum does not need to be continuous. Thus, IPR can calculate the competition of light among woody plant types.
Unlike individual-based radiation and vegetation models (e.g. Sato et al., 2007; Kobayashi and Iwabuchi, 2008), IPR calculates the solar radiation conditions of average individual woody crowns. IPR only calculates the solar radiation of one average individual plant for each woody stratum in the plant community rather than every individual woody plant. Thus it represents the conditions of typical plants of different strata. This is similar to the treatment of plant functional types in stand-based vegetation dynamic models (e.g. Sitch et al., 2003); therefore IPR could be used to improve the accuracy of light competition in these models. On the other hand, IPR focuses on solar radiation intercepted by crowns without considering directional reflectance to the sky (as some models for remote-sensing purposes, e.g. Li et al., 1995; Myneni et al., 1995; Kobayashi and Iwabuchi, 2008), thus it greatly simplifies the calculation and increases the computation efficiency.

Although the fraction of sunlit leaf area can be calculated numerically if we know the locations of all the plants in a community, the calculation is very time consuming - as we found in the random approach for the model testing, which needs to run about 300 random cases to get the average stabilized since the results are different for different random 
cases. Furthermore, the average of the random distribution calculated by the IPR is more ecologically meaningful than the individual random cases because the daily average light conditions of a plant is somewhat equivalent to the average of many random cases corresponding to different azimuth directions with the changes of time in a day. That is why the light conditions and the related ecological functions of one plant (e.g. photosynthesis, energy and water fluxes) averaged for a day or longer are similar to other plants of the same stratum although at any moment the light conditions can be very different from plant to plant. In addition to the solar radiation intercepted by individual woody plants and the herb strata, the IPR model also calculates the radiation condition on the ground, which is important for the growth of mosses and lichens, and for the whole ecosystems as well by directly affecting soil thermal and hydrological conditions, such as permafrost and active-layer thickness (Zhang et al., 2008). Since the IPR model is efficient in computation, it can be used for long-term, transient, spatial modelling for climate change impact assessment and predictions.
The crowns of woody plants in IPR are represented by rectangular boxes with uniform leaf area densities. Such a treatment allows for a quasi-analytical solution and greatly reduced computation time. For example, the interception of a light beam going through a slice of a crown can be expressed by Eq. (7). However, crowns can be of very different shapes, and non-foliage objects (the trunk and branches) also intercept light. The leaf area density is usually not uniform within a crown, and the radiative transfer process can be very complex. Therefore some modifications and improvements are needed in the future to make the model better reflecting the field conditions.

We developed the IPR model using Microsoft Visual $\mathrm{C}++$. The Supplement of the paper provides the code of the model to calculate the diurnal variations of solar radiation of different plant strata and on the ground in a day. It can be easily included as a module in vegetation models. A user's manual of the model is also included in the Supplement. 
Table A1. Notation.

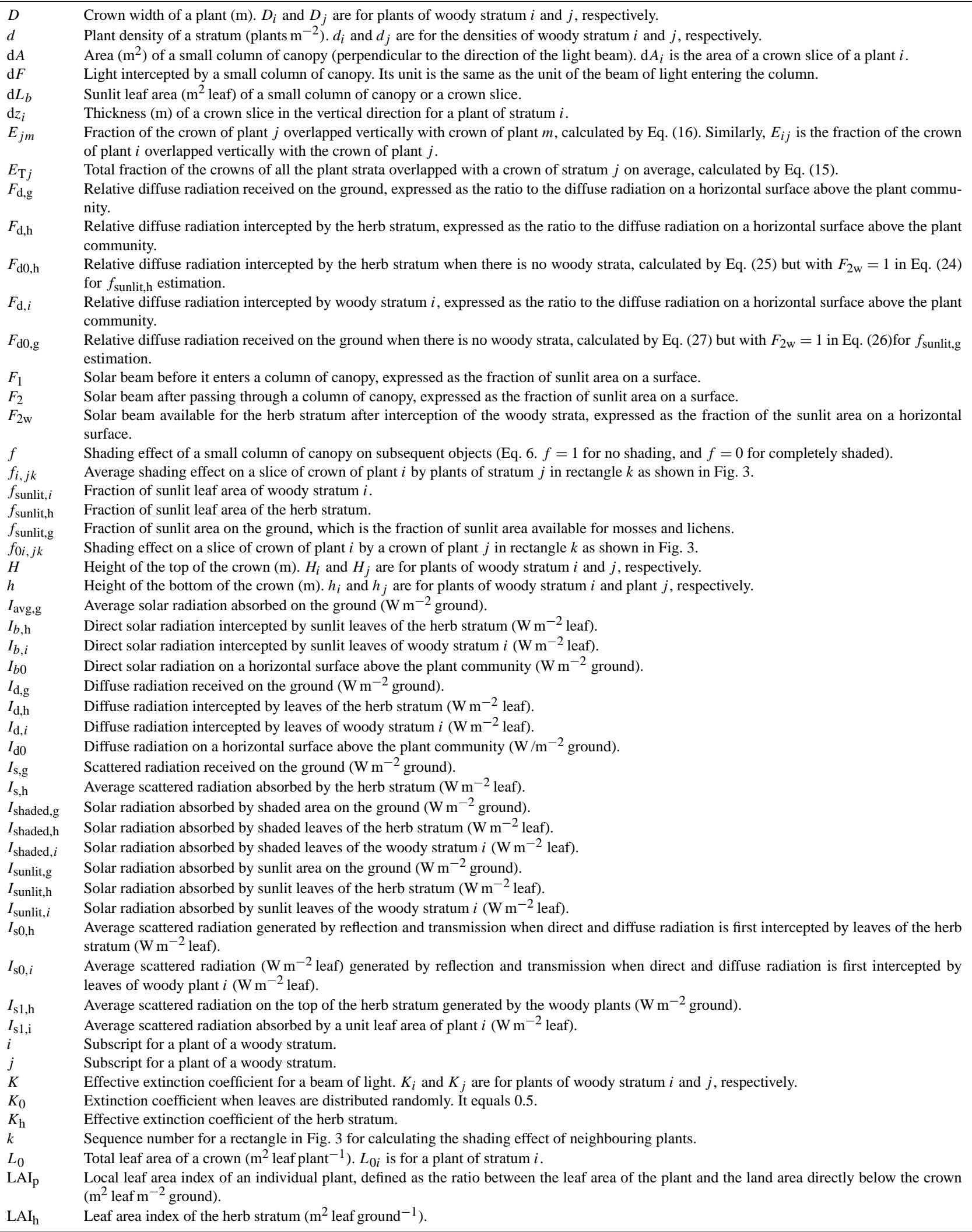


Table A1. Continued.

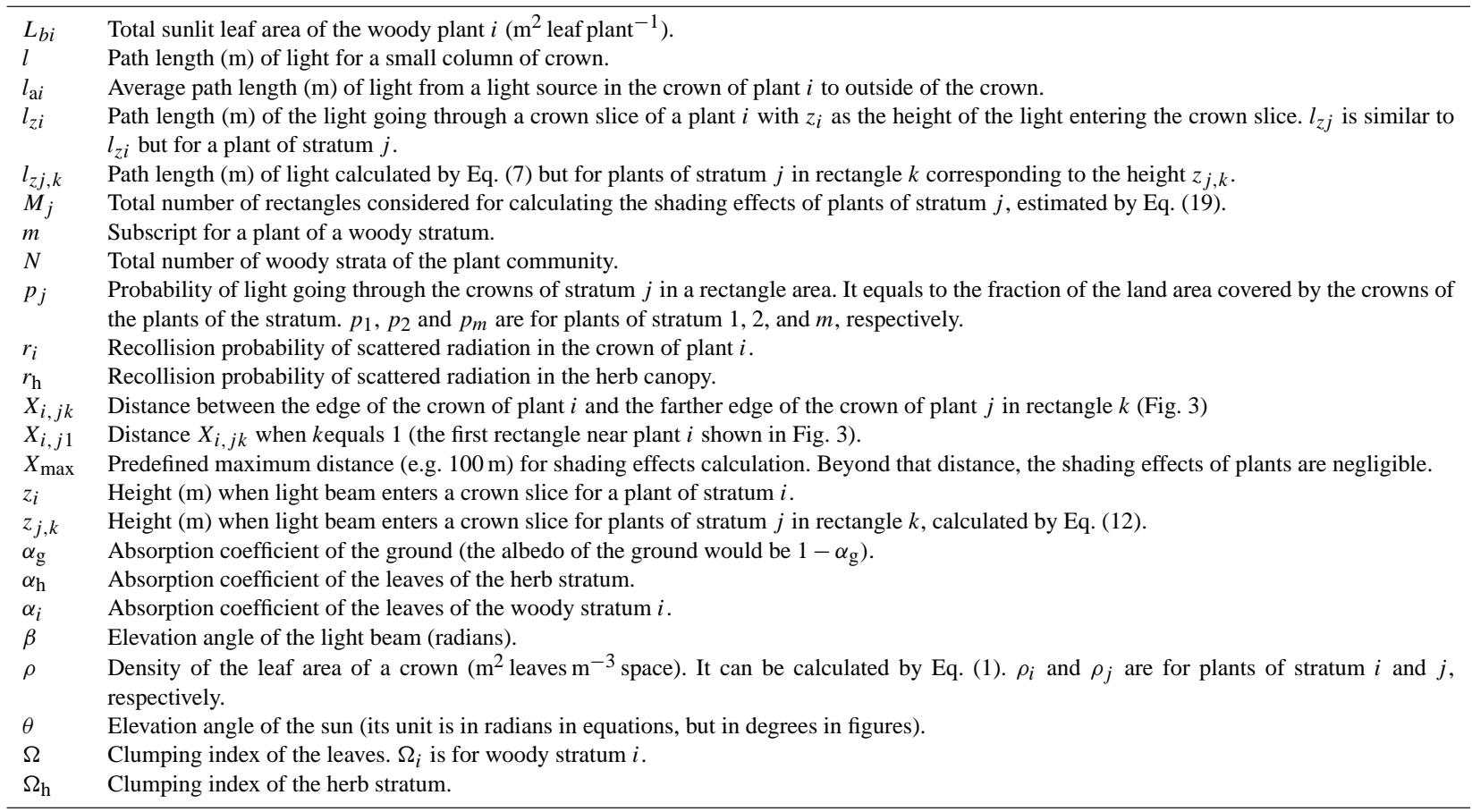




\section{The Supplement related to this article is available online at doi:10.5194/gmd-7-1357-2014-supplement.}

Acknowledgements. The authors would like to thank Zhaohua Chen and Ian Olthof for their critical internal review of the paper. Sylvain Leblanc and Xiping Wang also carefully reviewed the paper. This study was supported by the Cumulative Impact Monitoring Program in Northwest Territories (CIMP) and the Climate Change Geoscience Program in Natural Resources Canada (The Earth Science Sector Contribution number is 20100075).

Edited by: J. C. Hargreaves

\section{References}

Baldocchi, D. D. and Collineau, S.: The physical nature of solar radiation in heterogeneous canopies: spatial and temporal attributes, in: Exploitation of Environmental Heterogeneity by Plants, edited by: Caldwell, M. M. and Pearcy, R. M., Academic Press, San Diego, CA, 21-71, 1994.

Callaghan, T. V., Björn, L. O., Chapin III, F. S., Chernov, Y., Christensen, T. R., Huntley, B., Ims, R., Johansson, M., Riedlinger, D. J., Jonasson, S., Matveyeva, N., Oechel, W., Panikov, N., and Shaver, G.: Arctic tundra and polar desert ecosystems, in: Arctic Climate Impact Assessment, Cambridge University Press., 243352, 2005.

Cescatti, A.: Modeling the radiative transfer in discontinuous canopies of asymmetric crowns, I, Model structure and algorithms, Ecol. Model., 101, 263-274, 1997.

Chen, J. M. and Black, A.: Defining leaf area index for non-flat leaves, Plant Cell Environ., 15, 421-429, 1992.

Cramer, W., Bondeau, A., and Woodward, F. I.: Global response of terrestrial ecosystem structure and function to $\mathrm{CO}_{2}$ and climate change: results from six dynamic global vegetation models, Global Change Biol., 7, 357-373, doi:10.1046/j.13652486.2001.00383.x, 2001.

de Castro, F. and Fetcher, N.: Three dimensional model of the interception of light by a canopy, Agric. For. Meteor., 90, 215-233, 1998.

Dickinson, R.: Land surface processes and climate: Surface albedos and energy balance, Adv. Geophys., 25, 305-353, 1983.

Fankhauser, S., Leemans, R., Lin, E., Ogallo, L., Pittock, B., Richels, R., Rosenzweig, C., Safriel, U., Tol, R. S. J., Weyant, J., and Yohe, G.: Chapter 19. Vulnerability to climate change and reasons for concern: A synthesis, in: Climate Change 2001: Impacts, Adaptation and Vulnerability, Contribution of Work Group II to the Third Assessment Report of the Intergovernmental Panel on Climate Change, edited by: McCarthy, J. J., Canziani, O. F., Leary, N. A., Dokken, D. J., and White, K. S., Cambridge University Press, Cambridge, UK, 913-967, 2001.

Fischlin, A., Midgley, G. F., Price, J. T., Leemans, R., Gopal, B., Turley, C., Rounsevell, M. D. A., Dube, O. P., Tarazona, J., and Velichko, A. A.: Ecosystems, their properties, goods, and services, in: Climate Change 2007: Impacts, Adaptation and Vulnerability. Contribution of Working Group II to the Fourth Assessment Report of the Intergovernmental Panel on Climate Change, edited by: Parry, M. L., Canziani, O. F., Palutikof, J. P., van der Linden, P. J., and Hanson, C. E., Cambridge University Press, Cambridge, UK, 211-272, 2007.

Foley, J. A., Prentice, I. C., Ramankutty, N., Levis, S., Pollard, D., Sotch, S., and Haxeltine, A.: An integrated biosphere model of land surface processes, terrestrial carbon balance, and vegetation dynamics, Global Biogeochem. Cy., 10, 603-628, 1996.

Gamache, I. and Payette, S.: Height growth response of tree line black spruce to recent climate across the forest tundra of eastern Canada, J. Ecology, 92, 835-845, doi:10.1111/j.00220477.2004.00913.x, 2004.

Gastellu-Etchegorry, J. P., Martin, E., and Gascon, F.: DART: A 3-D model for simulating satellite images and surface radiation budget, Int. J. Remote Sens., 25, 73-96, doi:10.1080/0143116031000115166, 2004.

Goudriaan, J.: Crop Micrometeorology: A Simulation Study, Simulation Monographs, Pudoc, Wageningen, 236 pp., 1997.

Kobayashi, H. and Iwabuchi, H.: A coupled 1-D atmosphere and 3-D canopy radiative transfer model for canopy reflectance, light environment, and photosynthesis simulation in a heterogeneous landscape, Remote Sens. Environ., 112, 173-185, doi:10.1016/j.rse.2007.04.010, 2008.

Li, X., Strahler, A., and Woodcock, C. E.: A hybrid geometric optical-radiative transfer approach for modeling albedo and directional reflectance of discontinuous canopies, IEEE Trans. Geosci. Remote Sens., 33, 466-480, 1995.

Monsi, M. and Saeki, T.: Über den Lichtfaktor in den Pflanzengesellschaften und seine Bedeutung für die Stoffproduktion, Japanese J. Botany, 14, 22-52, 1953.

Myneni, R. B., Maggion, S., Iaquinta, J., Privette, J. L., Gobron, N., Pinty, B., Verstraete, M. M., Kimes, D. S., and Williams, D. L.: Optical remote sensing of vegetation: modeling, caveats, and algorithms, Remote Sens. Environ., 51, 169-188, 1995.

Norman, J. M.: Interfacing leaf and canopy irradiance interception models, in: Predicting Photosynthesis for Ecosystem Models, edited by: Hesketh, J. D. and Jones, J. W., Vol. II, CRC Press, Inc., Boca Raton, FL, 49-67, 1980.

Norman, J. M.: Simulation of microclimates, in: Biometeorology in Integrated Pest Management, edited by: Hatfield, J. L. and Thomason, I. J., Academic Press, New York, 65-99, 1982.

Norman, J. M.: Scaling processes between leaf and canopy levels, in: Scaling Physiological Processes: Leaf to Globe, edited by: Ehleringer, J. R. and Field, C. B., Academic Press, Inc., San Diego, CA, 41-76, 1993.

Oyarzun, R. A., Stöckle, C. O., and Whiting, M. D.: A simple approach to modeling radiation interception by fruit orchards, Agr. Forest Meteorol., 142, 12-24, doi:10.1016/j.agrformet.2006.10.004, 2007.

Overpeck, J., Whitlock, C., and Huntley, B.: Terrestrial biosphere dynamics in the climate system: past and future, in: Paleoclimate, Global Change and the Future, edited by: Alverson, K. D., Bradley, R. S., and Pedersen, T. F., Springer-Verlag, Berlin, 81111, 2003.

Panferov, O., Knyazikhin, Y., Myneni, R. B., Szarzynski, J., Engwald, S., Schnitzler, K. G., and Gravenhorst, G.: The role of canopy structure in the spectral variation of transmission and absorption of solar radiation in vegetation canopies, IEEE Trans. Geosci. Remote Sens., 39, 241-253, 2001. 
Prince, S. D.: Measurement of canopy interception of solar radiation by stands of trees in sparsely wooded savanna, Int. J. Remote Sens., 8, 1747-1766, 1987.

Ryel, R. J., Barnes, P. W., Beysehlag, W., Caldwell, M. M., and Flint, S. D.: Plant competition for light analyzed with a multispecies canopy model, I. Model development and influence of enhanced UV-B conditions on photosynthesis in mixed wheat and wild oat canopies, Oecologia, 82, 304-310, 1990.

Sato, H., Itoh, A., and Kohyama, T.: SEIB-DGVM: A new Dynamic Global Vegetation Model using a spatially explicit individual-based approach, Ecol. Modell., 200, 279-307, doi:10.1016/j.ecolmodel.2006.09.006, 2007.

Sellers P. J., Berry, J. A., Collatz, G. J., Field, C. B., and Hall, F. G.: Canopy reflectance, photosynthesis, and transpiration, III. A reanalysis using improved leaf models and a new canopy integration scheme, Remote Sens. Environ., 42, 187-216, 1992.

Sitch, S., Smith, B., Prentice, I. C., Arneth, A., Bondeau, A., Cramer, W., Kaplan, J., Levis, S., Lucht, W., Sykes, M. T., K. Thonicke, K., and Venevsky, S.: Evaluation of ecosystems dynamics, plant geography and terrestrial carbon cycling in the LPJ dynamic global vegetation model, Global Change Biol. 9, 161185, doi:10.1046/j.1365-2486.2003.00569.x, 2003.

Smolander, S. and Stenberg, P.: Simple parameterizations of the radiation budget of uniform broadleaved and coniferous canopies, Remote Sens. Environ., 94, 355-363, doi:10.1016/j.rse.2004.10.010, 2005.

Song, C. and Band, L. E.: MVP: a model to simulate the spatial patterns of photosynthetically active radiation under discrete forest canopies, Can. J. For. Res., 34, 1192-1203, doi:10.1139/X03280, 2004.

Sturm, M., Racine, C., and Tape, K.: Increasing shrub abundance in the Arctic, Nature, 411, 546-547, 2001.

Tape, K., Sturm, M., and Racine, C.: The evidence for shrub expansion in Northern Alaska and the Pan-Arctic, Global Change Biol., 12, 686-702, doi:10.1111/j.1365-2486.2006.01128.x, 2006.
Timoney, K. P., La Roi, G. H., Zoltai, S. C., and Robinson, A. L.: The high subarctic forest-tundra of northwestern Canada: position, width and vegetation gradients in relation to climate, Arctic, 45, 1-9, 1992.

Walker, M. D., Wahren, C. H., Hollister, R. D., Henry, G. H. R., Ahlquist, L. E., Alatalo, J. M., Bret-Harte, M. S., Calef, M. P., et al.: Plant community responses to experimental warming across the tundra biome, Proc. Natl. Acad Sci. USA, 103, 1342-1346, doi:10.1073/pnas.0503198103, 2006.

Wang, S., Trishchenko, A., and Sun, X.: Simulation of canopy radiation transfer and surface albedo in the EALCO model, Clim Dynam., 29, 615-632, doi:10.1007/s00382-007-0252-y, 2007.

Wang, Y.-P. and Leuning, R.: A two-leaf model for canopy conductance, photosynthesis and portioning of available energy. I: Model description and comparison with a multi-layered model, Agr. Forest Meteor., 91, 89-111, 1998.

Ward, J. S., Parker, G. R., and Ferrandino, F. J.: Long-term spatial dynamics in an old-growth deciduous forest, For. Ecol. Manag., 83, 189-202, 1996.

West, P. W. and Wells, K. F.: Method of application of a model to predict light environment of individual tree crowns and its use in a eucalypt forest., Ecol. Model., 60, 199-231, 1992.

Xu, L., Myneni, R. B., Chapin III, F. S., Callaghan, T. V., Pinzon, J. E., Tucker, C. J., Zhu, Z., Bi, J., Ciais, P., Tømmervik, H., Euskirchen, E. S., Forbes, B. C., Piao, S. L., Anderson, B. T., Ganguly, S., Nemani, R. R., Goetz, S. J., Beck, P. S. A., Bunn, A. G., Cao, C., and Stroeve, J. C.: Temperature and vegetation seasonality diminishment over northern lands, Nature Climate Change, 3, 581-586, doi:10.1038/nclimate1836, 2013.

Zhang, Y., Li., C., Trettin, C. C., Li, H., and Sun, G.: An integrated model of soil, hydrology and vegetation for carbon dynamics in wetland ecosystems, Global Biogeochem. Cy., 16, 1061, doi:10.1029/2001GB001838, 2002.

Zhang, Y., Chen, W., and Riseborough, D. W.: Disequilibrium response of permafrost thaw to climate warming in Canada over 1850-2100, Geophys. Res. Lett., 35, L02502. doi:10.1029/2007GL032117, 2008. 